\title{
Oxidation of Reduced Sulfur Species: Carbon Disulfide
}

\author{
Peter Glarborg, ${ }^{* \dagger}{ }^{\dagger}$ Birgitte Halaburt, ${ }^{\dagger}$ Paul Marshall, ${ }^{\ddagger}$ Adrian Guillory, ${ }^{\ddagger}$ Jürgen Troe, ${ }^{\S}$ Morten Thellefsen, \\ and Kurt Christensen \\ ${ }^{\dagger}$ Department of Chemical and Biochemical Engineering, Technical University of Denmark, DK-2800 Kgs. Lyngby, Denmark \\ ${ }^{*}$ Department of Chemistry and Center for Advanced Scientific Computing and Modeling (CASCaM), University of North Texas, \\ 1155 Union Circle \#305070, Denton, Texas 76203-5017, United States \\ ${ }^{\S}$ Institute of Physical Chemistry, University of Göttingen, D-37077 Göttingen, Germany \\ "Haldor Topsoe AS, DK-2800 Kgs. Lyngby, Denmark
}

\section{Supporting Information}

ABSTRACT: A detailed chemical kinetic model for oxidation of $\mathrm{CS}_{2}$ has been developed, on the basis of ab initio calculations for key reactions, including $\mathrm{CS}_{2}+\mathrm{O}_{2}$ and $\mathrm{CS}+\mathrm{O}_{2}$, and data from literature. The mechanism has been evaluated against experimental results from static reactors, flow reactors, and shock tubes. The $\mathrm{CS}_{2}+\mathrm{O}_{2}$ reaction forms OCS $+\mathrm{SO}$, with the lowest energy path involving crossing from the triplet to the singlet surface. For CS $+\mathrm{O}_{2}$, which yields OCS $+\mathrm{O}$, we found a high barrier to reaction, causing this step to be important only at elevated temperatures. The model predicts low temperature ignition delays and explosion limits accurately, whereas at higher temperatures it appears to overpredict both the induction time for $\mathrm{CS}_{2}$ oxidation and the formation rate of [O] upon ignition. The predictive capability of the model depends on the accuracy of the rate constant for the initiation step $\mathrm{CS}_{2}+\mathrm{O}_{2}$, which is

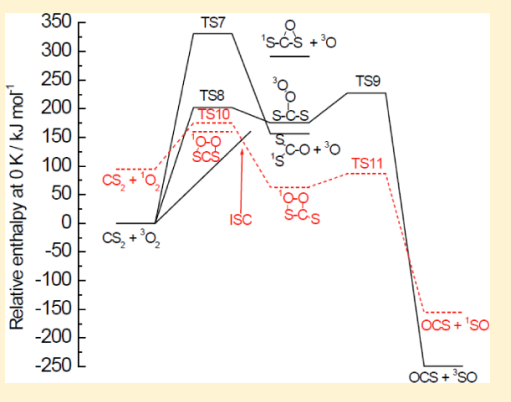
difficult to calculate due to the intersystem crossing, and the branching fraction for $\mathrm{CS}_{2}+\mathrm{O}$, which is measured only at low temperatures. The governing reaction mechanisms are outlined on the basis of calculations with the kinetic model.

\section{INTRODUCTION}

Off-gases containing carbon disulfide $\left(\mathrm{CS}_{2}\right)$ are produced together with other sulfur containing compounds such as $\mathrm{H}_{2} \mathrm{~S}$ from a range of industrial processes, including the Claus process ${ }^{1-3}$ and production of viscous fibers, ${ }^{4}$ and in gasification of coal ${ }^{5}$ and biomass. ${ }^{6}$ Similar to $\mathrm{H}_{2} \mathrm{~S}$ and the oxidation product $\mathrm{SO}_{2}$, carbon disulfide is toxic and harmful to the environment. Efficient treatment of the sulfur containing off gases becomes a bottleneck in these processes as strict emission requirements must be met. Hence, knowledge of the $\mathrm{CS}_{2}$ oxidation mechanism is important. Investigations have shown that $\mathrm{CS}_{2} /$ $\mathrm{O}_{2}$ mixtures are able to autoignite at low temperature and low pressure $^{7-13}$ under conditions of negligible self-heating. Two explosion limits have been reported in the literature, ${ }^{7-9}$ and studies have been carried out to determine the effect upon the limits with a change in surface conditions and addition of inert gases. The induction times range from a few seconds to several minutes. ${ }^{9,11,14}$ At higher temperatures, $\mathrm{CS}_{2}$ oxidation has been investigated in flow reactors, ${ }^{2,15}$ shock tubes, ${ }^{16-18}$ and laminar premixed flames. ${ }^{19-23}$ Much of the high-temperature work has been motivated by interest in the $\mathrm{CO}$ laser. $\mathrm{CS}_{2} / \mathrm{O}_{2}$ flames form $\mathrm{CO}$ with its vibrational population inverted, facilitating production of a $\mathrm{CO}$ flame laser.

Previous studies of the reaction mechanism of carbon disulfide oxidation have mostly been restricted to fuel-lean, dry conditions. ${ }^{17,18,20,24,25}$ No reported chemical kinetic models are found to satisfactory describe experimental data across a wider range of mixture composition, temperature, and pressure as the mechanism is complex and accurate kinetic data have been unavailable for several important reactions. The objective of the present study is to develop a detailed chemical kinetic model for oxidation of $\mathrm{CS}_{2}$ and evaluate it over a broad range of conditions. The work is a continuation of a recent study by Glarborg and Marshall ${ }^{26}$ on the oxidation chemistry of carbonyl sulfide. Rate constants for reactions $\mathrm{CS}_{2}$ with $\mathrm{O}_{2}$ and $\mathrm{SO}_{2}$ and for CS with $\mathrm{O}_{2}$ and $\mathrm{SO}$ are calculated from ab initio theory. The mechanism aims at describing moist as well as dry oxidation conditions and includes reactions with hydrogencontaining radicals such as $\mathrm{H}, \mathrm{OH}, \mathrm{HO}_{2}$, and $\mathrm{SH}$. The resulting model is evaluated by comparing predictions with reported experimental results from static reactors, flow reactors, and shock tubes.

\section{DETAILED KINETIC MODEL}

In the present study, the starting mechanism and corresponding thermodynamic properties were drawn from earlier work on oxidation of $\mathrm{CO} / \mathrm{H}_{2}{ }^{27,28}$ and on sulfur chemistry. ${ }^{29-34}$ The $\mathrm{CS}_{2}$ oxidation subset of the mechanism was developed in the present work, whereas reactions of OCS were drawn from recent work of the authors. ${ }^{26}$ An ozone subset was compiled from the evaluation of Atkinson et al. ${ }^{35}$ The thermodynamic properties for selected species in the sulfur subset are shown in

Received: June 11, 2014

Revised: $\quad$ August 1, 2014

Published: August 4, 2014 
Table 1. Thermodynamic Properties of Selected Species in the Reaction Mechanisma

\begin{tabular}{|c|c|c|c|c|c|c|c|c|c|c|}
\hline species & $H_{298}$ & $S_{298}$ & $C_{p, 300}$ & $C_{p, 400}$ & $C_{p, 500}$ & $C_{p, 600}$ & $C_{p, 800}$ & $C_{p, 1000}$ & $C_{p, 1500}$ & ref \\
\hline $\mathrm{CS}_{3}$ & 264.5 & 291.8 & 62.64 & 68.50 & 72.48 & 75.12 & 78.05 & 79.68 & 81.61 & 36, pw \\
\hline $\mathrm{CS}_{2}$ & 116.8 & 238.0 & 45.60 & 49.62 & 52.34 & 54.31 & 57.19 & 58.87 & 61.00 & 37 \\
\hline CS & 278.7 & 210.7 & 29.85 & 30.94 & 32.16 & 33.25 & 34.75 & 35.67 & 36.76 & 37 \\
\hline OCS & -141.8 & 231.8 & 41.66 & 45.89 & 48.90 & 51.17 & 54.52 & 56.78 & 59.75 & 37 \\
\hline $\mathrm{OCS}_{2}$ & 25.8 & 279.9 & 58.74 & 64.69 & 68.79 & 71.68 & 75.24 & 77.46 & 80.35 & 26,38 \\
\hline SO & 5.02 & 222.1 & 30.19 & 31.61 & 32.83 & 33.83 & 35.26 & 36.09 & 37.47 & 37 \\
\hline $\mathrm{SO}_{2}$ & -297.0 & 248.3 & 39.94 & 43.55 & 46.60 & 49.07 & 52.46 & 54.52 & 56.99 & 37 \\
\hline S & 277.1 & 167.9 & 23.70 & 23.32 & 22.78 & 22.28 & 21.81 & 21.48 & 21.19 & 37 \\
\hline $\mathrm{SH}$ & 143.1 & 195.9 & 32.45 & 31.86 & 31.36 & 31.15 & 31.86 & 32.78 & 34.92 & 37 \\
\hline $\mathrm{S}_{2}$ & 128.5 & 228.4 & 32.53 & 34.00 & 35.00 & 35.67 & 36.47 & 37.31 & 38.90 & 37 \\
\hline $\mathrm{S}_{2} \mathrm{O}$ & -57.7 & 266.5 & 43.88 & 47.44 & 50.04 & 51.88 & 54.22 & 55.52 & 56.94 & 34 \\
\hline
\end{tabular}

Table 1. The data are mostly drawn from the database of Goos, Burcat, and Ruscic. ${ }^{37}$

Table 2 lists the key reactions in the $\mathrm{CS}_{2}$ oxidation scheme with the rate coefficients used in the present work. The full mechanism is available as Supporting Information. The $\mathrm{CS}_{2}$ oxidation subset mostly relies on rate constants obtained from literature or estimated by analogy. However, in the present work we characterize the key reactions of $\mathrm{CS}_{2}$ and CS with $\mathrm{O}_{2}$, as well as the minor steps $\mathrm{CS}_{2}+\mathrm{SO}_{2}$ and $\mathrm{CS}+\mathrm{SO}$ which have been proposed in prior modeling, by ab initio calculations.

Available experimental data on $\mathrm{CS}_{2}$ oxidation from the literature are largely obtained under conditions with at most trace concentrations of water vapor. For this reason, the important radicals are $\mathrm{O}, \mathrm{CS}, \mathrm{S}$, and $\mathrm{SO}$, whereas chain carriers such as $\mathrm{H}, \mathrm{OH}, \mathrm{HO}_{2}$, and $\mathrm{SH}$ have at most a minor influence. In industrial processes, however, $\mathrm{CS}_{2}$ is typically present together with $\mathrm{H}_{2} \mathrm{~S}$ and water vapor, and we have chosen to include in the mechanism also species and chain carriers involving hydrogen.

Ab Initio Calculations. A key reaction in oxidation of carbon disulfide is $\mathrm{CS}+\mathrm{O}_{2}$. Three product channels have been proposed for this reaction:

$$
\begin{aligned}
& \mathrm{CS}+\mathrm{O}_{2} \rightleftharpoons \mathrm{OCS}+\mathrm{O} \\
& \mathrm{CS}+\mathrm{O}_{2} \rightleftharpoons \mathrm{CO}+\mathrm{SO} \\
& \mathrm{CS}+\mathrm{O}_{2} \rightleftharpoons \mathrm{CO}_{2}+\mathrm{S}
\end{aligned}
$$

The reaction numbering refers to the listing in Table 2. Both the overall rate constant and the products of reaction are in discussion. Atkinson et al. ${ }^{35}$ based their recommendation for the overall rate constant on the work of Black et al. ${ }^{41}$ at $298 \mathrm{~K}$. However, the reaction is slow at this temperature and difficult to quantify. Results from photochemical and explosion limit studies ${ }^{9,42}$ indicate a comparable importance of channels R16 and R16', but in the more direct flow system study of Richardson, ${ }^{21} k_{16}{ }^{\prime}$ was found to be at least an order of magnitude smaller than $k_{16}$. In a more recent high-temperature shock tube study, Murakami et al. ${ }^{25}$ considered only channel $\mathrm{R} 16$ as a plausible path for the $\mathrm{CS}+\mathrm{O}_{2}$ reaction and measured the value of $k_{16}$ to be $(6.1 \pm 0.6) \times 10^{12} \exp (-(6140 \pm 8150) /$ T) $\mathrm{cm}^{3} \mathrm{~mol}^{-1} \mathrm{~s}^{-1}$ in the $2000-2900 \mathrm{~K}$ range. Note the substantial uncertainty in the activation energy.

The potential energy surface for $\mathrm{CS}+\mathrm{O}_{2}$ (R16) was explored using density functional theory (DFT) and QCISD theory. No four-center R16' or complex bond rearrangement R16" pathways were found and accordingly we consider it unlikely that product channels other than OCS + O R16 are active. The abstraction path leading to OCS + O was characterized using the W1U method ${ }^{43}$ as implemented in the Gaussian 09 program. ${ }^{44}$ We modified this method to base it on geometry optimization and vibrational frequencies at the QCISD/6-311G(2d,d,p) level of theory, followed by several component steps that are combined to yield an approximate coupled cluster $(\operatorname{CCSD}(\mathrm{T}))$ energy at the infinite basis set limit, with corrections for core-valence electron correlation and scalar relativistic effects. The resulting potential energy diagram (PED) is shown in Figure 1. Reaction proceeds via addition over a $119 \mathrm{~kJ} \mathrm{~mol}^{-1}$ barrier to form an SCOO adduct that then dissociates over a lower barrier $\left(100 \mathrm{~kJ} \mathrm{~mol}^{-1}\right.$ relative to $\mathrm{CS}+\mathrm{O}_{2}$ ) to yield OCS $+\mathrm{O}$. There are trans and cis pathways, with the former having a marginally lower entrance barrier, by $1.7 \mathrm{~kJ} \mathrm{~mol}^{-1}$. Using DFT, the corresponding cis adduct is not bound and therefore was not explored further. The overall $0 \mathrm{~K}$ reaction enthalpy is computed at $-176 \mathrm{~kJ}$ $\mathrm{mol}^{-1}$ (cf. a literature value of $-175 \mathrm{~kJ} \mathrm{~mol}^{-1}$ depending on the source of the thermo data). The cis/trans reaction path degeneracy is taken into account by a symmetry factor of 2 for the hindered torsion in the trans entrance transition state (TS), which has a frequency of $78 \mathrm{~cm}^{-1}$. The detailed Cartesian coordinates, vibrational frequencies, and energies are listed in the Supporting Information. These data are employed in canonical transition state theory (TST) as implemented in Multiwell, ${ }^{45}$ along with the assumption that the first barrier is rate determining, to obtain the rate constant $1.3 \times 10^{7} T^{1.97}$ $\exp (-14140 / T) \mathrm{cm}^{3} \mathrm{~mol}^{-1} \mathrm{~s}^{-1}$, for $T=500-2500 \mathrm{~K}$. Although the exit barrier from the adduct is $\sim 20 \mathrm{~kJ} \mathrm{~mol}^{-1}$ below the entrance barrier, this transition state is also tighter. The computed $A$ factor at $1000 \mathrm{~K}$ for adduct dissociation to OCS + $\mathrm{O}$ is $2.2 \times 10^{13} \mathrm{~s}^{-1}$ at the high-pressure limit, 6.7 times smaller than that for dissociation back to $\mathrm{CS}+\mathrm{O}_{2}$. This would suggest that above $\sim 1400 \mathrm{~K}$ it is the second barrier that becomes rate limiting. However, because the cis pathway appears to have no barrier, in fact rapid rotation allows for fast overall dissociation limited by the initial rate of adduct formation. For comparison, computed pathways for $\mathrm{CO}+\mathrm{O}_{2}$ abstraction proceed via similar TSs but without subsequent bound adducts, and the cis and trans barriers are higher at 260 and $318 \mathrm{~kJ} \mathrm{~mol}^{-1}$, respectively. $^{46}$

Figure 2 shows an Arrhenius plot for the reaction of CS with $\mathrm{O}_{2}$. The calculated activation energy is consistent with the wide range of values quoted for the valence iso-electronic reaction $\mathrm{CO}+\mathrm{O}_{2}$, but it makes $\mathrm{CS}+\mathrm{O}_{2}$ too slow to be consistent with the low temperature observations of Black et al. ${ }^{41}$ and Richardson. ${ }^{21}$ It is larger than the value derived by Murakami 
Table 2. Reaction Subset for Carbon Disulfide Oxidation ${ }^{a}$

\begin{tabular}{|c|c|c|c|c|c|}
\hline & & $A\left[\mathrm{~cm} \mathrm{~mol}^{-1} \mathrm{~s}^{-1}\right]$ & $\beta$ & $E_{\mathrm{a}} / R[\mathrm{~K}]$ & source \\
\hline \multirow[t]{2}{*}{1.} & $\mathrm{CS}+\mathrm{S}(+\mathrm{M}) \rightleftharpoons \mathrm{CS}_{2}(+\mathrm{M})$ & $1.9 \times 10^{26}$ & -4.300 & 0 & 39 \\
\hline & low pressure limit: & $6.2 \times 10^{23}$ & -2.420 & 0 & \\
\hline 2. & $\mathrm{CS}+\mathrm{SH} \rightleftharpoons \mathrm{CS}_{2}+\mathrm{H}$ & $1.2 \times 10^{13}$ & 0.000 & 0 & see text \\
\hline 3. & $\mathrm{CS}_{2}+\mathrm{O} \rightleftharpoons \mathrm{CS}+\mathrm{SO}$ & $3.2 \times 10^{13}$ & 0.000 & 820 & see text \\
\hline 4. & $\mathrm{CS}_{2}+\mathrm{O} \rightleftharpoons \mathrm{OCS}+\mathrm{S}$ & $2.9 \times 10^{12}$ & 0.000 & 820 & see text \\
\hline 5. & $\mathrm{CS}_{2}+\mathrm{O} \rightleftharpoons \mathrm{CO}+\mathrm{S}_{2}$ & $1.6 \times 10^{12}$ & 0.000 & 820 & see text \\
\hline \multirow[t]{4}{*}{6.} & $\mathrm{CS}_{2}+\mathrm{OH}(+\mathrm{M}) \rightarrow \mathrm{HOCS}_{2}(+\mathrm{M})$ & $4.8 \times 10^{12}$ & 0.000 & 0 & 35 \\
\hline & low pressure limit: & $2.9 \times 10^{17}$ & 0.000 & 0 & \\
\hline & $\mathrm{HOCS}_{2}(+\mathrm{M}) \rightarrow \mathrm{CS}_{2}+\mathrm{OH}(+\mathrm{M})$ & $1.6 \times 10^{13}$ & 0.000 & 5159 & 35 \\
\hline & low pressure limit: & $9.6 \times 10^{17}$ & 0.000 & 5159 & $(\mathrm{Fc}=0.8)$ \\
\hline 7. & $\mathrm{CS}_{2}+\mathrm{O}_{2} \rightleftharpoons \mathrm{OCS}+\mathrm{SO}$ & $1.6 \times 10^{13}$ & 0.000 & 31000 & pw \\
\hline 8. & $\mathrm{CS}_{2}+\mathrm{O}_{2} \rightleftharpoons \mathrm{OCS}+{ }^{1} \mathrm{SO}$ & $3.6 \times 10^{11}$ & 0.000 & 17900 & pw \\
\hline \multirow[t]{2}{*}{9.} & $\mathrm{CS}_{2}+\mathrm{S}(+\mathrm{M}) \rightleftharpoons \mathrm{CS}_{3}(+\mathrm{M})$ & $1.3 \times 10^{12}$ & 0.000 & 0 & 36 \\
\hline & low pressure limit: & $2.5 \times 10^{21}$ & -1.600 & 0 & \\
\hline 10. & $\mathrm{CS}_{2}+\mathrm{S} \rightleftharpoons \mathrm{CS}+\mathrm{S}_{2}$ & $6.9 \times 10^{13}$ & 0.000 & 4447 & 36 \\
\hline 11. & $\mathrm{CS}_{2}+\mathrm{SO} \rightleftharpoons \mathrm{CS}+\mathrm{S}_{2} \mathrm{O}$ & $1.0 \times 10^{12}$ & 0.000 & 5030 & est \\
\hline 12. & $\mathrm{CS}_{2}+\mathrm{SO}_{2} \rightleftharpoons \mathrm{OCS}+\mathrm{S}_{2} \mathrm{O}$ & $7.8 \times 10^{12}$ & 0.000 & 24460 & pw \\
\hline 13. & $\mathrm{CS}+\mathrm{O} \rightleftharpoons \mathrm{CO}+\mathrm{S}$ & $1.6 \times 10^{14}$ & 0.000 & 760 & 35 \\
\hline 14. & $\mathrm{CS}+\mathrm{OH} \rightleftharpoons \mathrm{OCS}+\mathrm{H}$ & $1.0 \times 10^{14}$ & 0.000 & 0 & 40 , est \\
\hline 15. & $\mathrm{CS}+\mathrm{OH} \rightleftharpoons \mathrm{CO}+\mathrm{SH}$ & $2.0 \times 10^{13}$ & 0.000 & 0 & 40 , est \\
\hline 16. & $\mathrm{CS}+\mathrm{O}_{2} \rightleftharpoons \mathrm{OCS}+\mathrm{O}$ & $1.3 \times 10^{7}$ & 1.970 & 14140 & pw \\
\hline 17. & $\mathrm{CS}+\mathrm{OCS} \rightleftharpoons \mathrm{CS}_{2}+\mathrm{CO}$ & $2.0 \times 10^{12}$ & 0.000 & 18970 & est as $\mathrm{OCS}+\mathrm{SO}$ \\
\hline 18. & $\mathrm{CS}+\mathrm{SO} \rightleftharpoons \mathrm{OCS}+\mathrm{S}$ & $3.6 \times 10^{5}$ & 2.193 & 1744 & pw \\
\hline 19. & $\mathrm{CS}+\mathrm{SO}_{2} \rightleftharpoons \mathrm{OCS}+\mathrm{SO}$ & $2.7 \times 10^{12}$ & 0.000 & 12230 & est as $\mathrm{CO}+\mathrm{SO}_{2}$ \\
\hline 20. & $\mathrm{OCS}+\mathrm{M} \rightleftharpoons \mathrm{CO}+\mathrm{S}+\mathrm{M}$ & $2.5 \times 10^{14}$ & 0.000 & 30900 & 26 \\
\hline 21. & $\mathrm{OCS}+\mathrm{H} \rightleftharpoons \mathrm{CO}+\mathrm{SH}$ & $2.2 \times 10^{11}$ & 1.022 & 2810 & 26 \\
\hline \multirow[t]{2}{*}{22.} & $\mathrm{OCS}+\mathrm{O} \rightleftharpoons \mathrm{CO}+\mathrm{SO}$ & $4.7 \times 10^{13}$ & 0.000 & 2617 & $26, b$ \\
\hline & & $-2.0 \times 10^{13}$ & 0.000 & 3717 & \\
\hline 23. & $\mathrm{OCS}+\mathrm{O} \rightleftharpoons \mathrm{CO}_{2}+\mathrm{S}$ & $2.0 \times 10^{13}$ & 0.000 & 3717 & 26 \\
\hline 24. & $\mathrm{OCS}+\mathrm{OH} \rightleftharpoons \mathrm{CO}_{2}+\mathrm{SH}$ & $4.6 \times 10^{11}$ & 0.000 & 8072 & 26 \\
\hline 25. & $\mathrm{OCS}+\mathrm{O}_{2} \rightleftharpoons \mathrm{CO}+\mathrm{SO}_{2}$ & $1.0 \times 10^{12}$ & 0.000 & 16100 & 26 \\
\hline 26. & $\mathrm{OCS}+\mathrm{S} \rightleftharpoons \mathrm{CO}+\mathrm{S}_{2}$ & $4.0 \times 10^{4}$ & 2.570 & 1180 & 26 \\
\hline \multirow[t]{4}{*}{27.} & $\mathrm{OCS}+\mathrm{S} \rightleftharpoons \mathrm{OCS}_{2}$ & $4.6 \times 10^{33}$ & -8.220 & 4769 & $0.066 \mathrm{~atm}^{26, b}$ \\
\hline & & $1.1 \times 10^{31}$ & -6.980 & 4206 & $0.066 \mathrm{~atm}$ \\
\hline & & $2.4 \times 10^{34}$ & -8.220 & 4769 & $0.66 \mathrm{~atm}$ \\
\hline & & $5.7 \times 10^{31}$ & -6.980 & 4206 & $0.66 \mathrm{~atm}$ \\
\hline 28. & $\mathrm{OCS}+\mathrm{SH} \rightleftharpoons \mathrm{CS}_{2}+\mathrm{OH}$ & $1.2 \times 10^{12}$ & 0.000 & 25670 & est \\
\hline 29. & $\mathrm{OCS}+\mathrm{SO} \rightleftharpoons \mathrm{CO}+\mathrm{S}_{2} \mathrm{O}$ & $2.0 \times 10^{12}$ & 0.000 & 18970 & 26 \\
\hline 30. & $\mathrm{CS}_{3}+\mathrm{O} \rightleftharpoons \mathrm{CS}_{2}+\mathrm{SO}$ & $6.0 \times 10^{13}$ & 0.000 & 0 & est \\
\hline 31. & $\mathrm{CS}_{3}+\mathrm{S} \rightleftharpoons \mathrm{CS}_{2}+\mathrm{S}_{2}$ & $6.0 \times 10^{13}$ & 0.000 & 0 & est \\
\hline 32. & $\mathrm{OCS}_{2}+\mathrm{O} \rightleftharpoons \mathrm{OCS}+\mathrm{SO}$ & $6.0 \times 10^{13}$ & 0.000 & 0 & 26 \\
\hline 33. & $\mathrm{OCS}_{2}+\mathrm{S} \rightleftharpoons \mathrm{OCS}+\mathrm{S}_{2}$ & $6.0 \times 10^{13}$ & 0.000 & 0 & 26 \\
\hline 34. & $\mathrm{OCS}_{2}+\mathrm{O}_{2} \rightleftharpoons \mathrm{OCS}+\mathrm{SO}_{2}$ & $1.0 \times 10^{12}$ & 0.000 & 0 & est \\
\hline 35. & $\mathrm{HOCS}_{2}+\mathrm{O}_{2} \rightarrow \mathrm{OCS}+\mathrm{HOSO}$ & $1.4 \times 10^{10}$ & 0.000 & 0 & 35 \\
\hline 37. & $\mathrm{HOCS}_{2}+\mathrm{O}_{2} \rightarrow \mathrm{HCO}+\mathrm{SO}_{2}+\mathrm{S}$ & $0.3 \times 10^{10}$ & 0.000 & 0 & 35 \\
\hline 38. & $\mathrm{~S}+\mathrm{O}_{2} \rightleftharpoons \mathrm{SO}+\mathrm{O}$ & $5.4 \times 10^{5}$ & 2.110 & -730 & 53 \\
\hline 39. & $\mathrm{SO}+\mathrm{O}_{2} \rightleftharpoons \mathrm{SO}_{2}+\mathrm{O}$ & $7.6 \times 10^{3}$ & 2.370 & 1495 & 54 \\
\hline 40. & $\mathrm{O}+\mathrm{O}_{2}+\mathrm{M} \rightleftharpoons \mathrm{O}_{3}+\mathrm{M}$ & $5.6 \times 10^{20}$ & -2.600 & 0 & 35 \\
\hline 41. & $\mathrm{O}_{3}+\mathrm{O} \rightleftharpoons \mathrm{O}_{2}+\mathrm{O}_{2}$ & $4.8 \times 10^{12}$ & 0.000 & 2060 & 35 \\
\hline 42. & $\mathrm{O}_{3}+\mathrm{OH} \rightleftharpoons \mathrm{O}_{2}+\mathrm{HO}_{2}$ & $1.0 \times 10^{12}$ & 0.000 & 936 & 35 \\
\hline 43. & $\mathrm{O}_{3}+\mathrm{HO}_{2} \rightleftharpoons \mathrm{O}_{2}+\mathrm{O}_{2}+\mathrm{OH}$ & $5.8 \times 10^{-4}$ & 4.570 & -693 & 35 \\
\hline 44. & $\mathrm{CS}+\mathrm{O}_{3} \rightleftharpoons \mathrm{OCS}+\mathrm{O}_{2}$ & $4.5 \times 10^{12}$ & 0.000 & 3020 & 35 , est \\
\hline 45. & $\mathrm{~S}+\mathrm{O}_{3} \rightleftharpoons \mathrm{O}_{2}+\mathrm{SO}$ & $7.2 \times 10^{12}$ & 0.000 & 0 & 35 \\
\hline 46. & $\mathrm{SO}+\mathrm{O}_{3} \rightleftharpoons \mathrm{O}_{2}+\mathrm{SO}_{2}$ & $2.7 \times 10^{12}$ & 0.000 & 1170 & 35 \\
\hline
\end{tabular}

${ }^{a}$ Parameters for use in the modified Arrhenius expression $k=A T^{\beta} \exp \left(-E_{\mathrm{a}} /[R T]\right)$. Units are mol, $\mathrm{cm}, \mathrm{s}, \mathrm{K} .{ }^{b}$ Duplicate reaction; the rate constant is calculated by adding the two Arrhenius expressions.

et al. $^{25}$ from shock tube experiments, but within their reported uncertainty. The calculated value of $k_{16}$ is in agreement with the scattered data reported by Murakami et al., at least in the upper part of their temperature range. Two critical reviews of this reaction in the context of low temperature chemistry ${ }^{35,47}$ accepted the measurements at room temperature but, because 


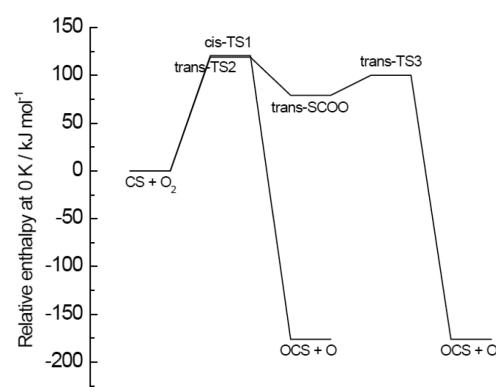

Figure 1. Potential energy diagram for $\mathrm{CS}+\mathrm{O}_{2}$ based on W1U results.

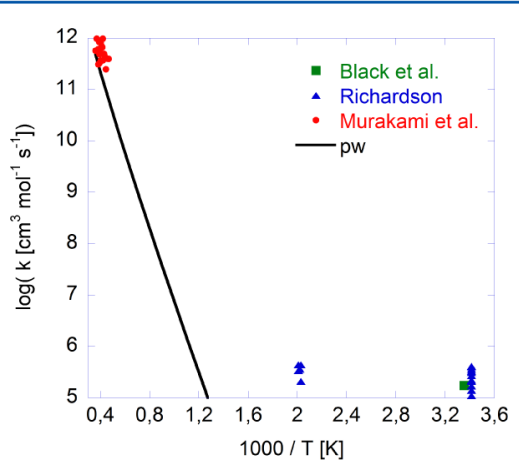

Figure 2. Arrhenius plot for the reaction $\mathrm{CS}+\mathrm{O}_{2}$. Experimental results (symbols) from Black et al., ${ }^{41}$ Richardson, ${ }^{21}$ and Murakami et al. $^{25}$ The solid line denotes the rate constant calculated in the present work.

the data of Richardson et al. imply an almost zero activation energy and an extraordinarily small $A$ factor, made no recommendation concerning the temperature dependence. The present computations might not contradict the measured rate constants below $600 \mathrm{~K}$ if there is a further channel other than $\mathrm{O}$ atom abstraction from $\mathrm{O}_{2}$. However, one should be mindful of the great difficulty of isolating very slow processes from interference by impurities or secondary chemistry. The $\mathrm{CS}+\mathrm{O}_{2}$ reaction deserves further investigation, especially above $600 \mathrm{~K}$.

Other processes were investigated using the lower-cost CBSQB3 approximation, ${ }^{48}$ which begins with B3LYP/6-311G$(2 \mathrm{~d}, \mathrm{~d}, \mathrm{p})$ geometries and frequencies followed by several steps that are combined to approximate the $\operatorname{CCSD}(\mathrm{T})$ energy at the infinite basis set limit. Chernysheva et al. ${ }^{24}$ included the reaction of $\mathrm{CS}$ with $\mathrm{SO}$, assuming two product channels,

$$
\begin{aligned}
& \mathrm{CS}+\mathrm{SO} \rightleftharpoons \mathrm{OCS}+\mathrm{S} \\
& \mathrm{CS}+\mathrm{SO} \rightleftharpoons \mathrm{CO}+\mathrm{S}_{2}
\end{aligned}
$$

Reaction R18' is a four-center reaction, and the occurrence of this step is not supported by our ab initio calculations.

Figure 3 shows the PED for CS + SO R18, which, like the oxygen analog R16, proceeds via an addition/dissociation path, but with much lower barriers. TST was applied to the initial, higher barrier at TS4 to determine the rate constant. For reaction R18, our calculated rate constant is considerably smaller than the value proposed by Chernysheva et al. at low temperatures but faster above $1000 \mathrm{~K}$. We also looked at the reaction of $\mathrm{CS}_{2}$ with $\mathrm{SO}_{2}$,

$$
\mathrm{CS}_{2}+\mathrm{SO}_{2} \rightleftharpoons \mathrm{OCS}+\mathrm{S}_{2} \mathrm{O}
$$

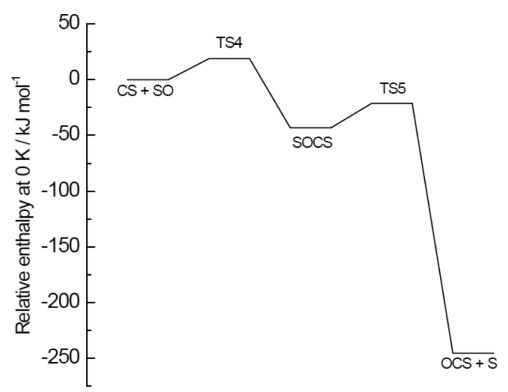

Figure 3. Potential energy diagram for $\mathrm{CS}+\mathrm{SO}$ based on CBS-QB3 results.

The simple PED for atom exchange between $\mathrm{CS}_{2}$ and $\mathrm{SO}_{2}$ is shown in Figure 4. As expected, the reaction is slow, with a calculated activation energy of $203 \mathrm{~kJ} \mathrm{~mol}^{-1}$.

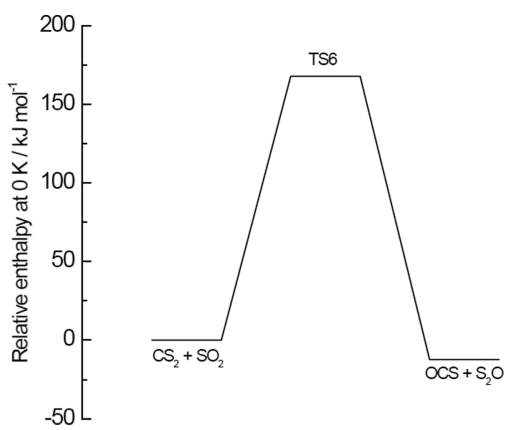

Figure 4. Potential energy diagram for $\mathrm{CS}_{2}+\mathrm{SO}_{2}$ based on CBS-QB3 results.

The reaction of $\mathrm{CS}_{2}$ with $\mathrm{O}_{2}$ is important for initiation of $\mathrm{CS}_{2}$ oxidation at higher temperatures. It was investigated by Saito et al. ${ }^{18}$ in a shock tube study of $\mathrm{CS}_{2}$ oxidation under conditions with a large excess of $\mathrm{O}_{2}$ and Ar. Saito et al. assumed that the major product channel led to formation of $\mathrm{CS}$ and $\mathrm{SO}_{2}$ and derived a rate constant for this step from simulations with a complex mechanism. However, the activation energy derived by Saito et al. of $134 \mathrm{~kJ} \mathrm{~mol}^{-1}$ for $\mathrm{CS}_{2}+\mathrm{O}_{2}$ is significantly lower than the computed barrier of $247 \mathrm{~kJ} \mathrm{~mol}^{-1}$ for addition of $\mathrm{O}_{2}$ to $\mathrm{CS}_{2}{ }^{49}$ indicating that more work is required on this reaction.

We investigated a number of pathways for the reaction between $\mathrm{CS}_{2}$ and $\mathrm{O}_{2}$, as shown on Figure 5. The highest energy path is abstraction by the central carbon atom to yield $\mathrm{CS}_{2} \mathrm{O}+$ $\mathrm{O}$, which with a barrier of $332 \mathrm{~kJ} \mathrm{~mol}^{-1}$ will be too slow to be significant under most combustion conditions. The most favorable spin-allowed pathway involves addition over a barrier

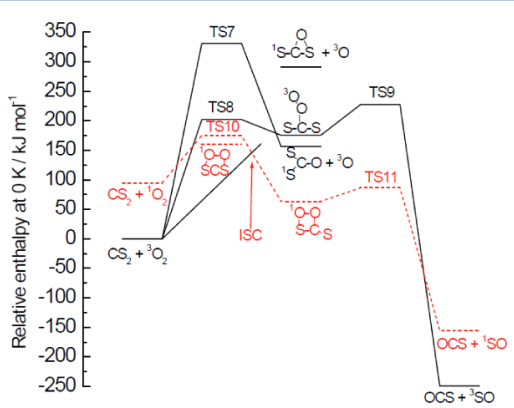

Figure 5. Potential energy diagram for $\mathrm{CS}_{2}+\mathrm{O}_{2}$ based on CBS-QB3 results. 
of $202 \mathrm{~kJ} \mathrm{~mol}^{-1}$ to make a triplet $\mathrm{CS}_{2} \mathrm{OO}$ adduct, followed by dissociation over a second, slightly higher barrier of $227 \mathrm{~kJ}$ $\mathrm{mol}^{-1}$ (relative to the reactants) to form OCS $+\mathrm{SO}$,

$$
\mathrm{CS}_{2}+\mathrm{O}_{2} \rightleftharpoons \mathrm{OCS}+\mathrm{SO}
$$

The second barrier, TS9, is also tighter than the first, TS8. For example, at $1000 \mathrm{~K}$ the $A$ factors at the high-pressure limit for dissociation of the triplet $\mathrm{CS}_{2} \mathrm{O}_{2}$ adduct via TS8 and TS9 are $3 \times 10^{13}$ and $8 \times 10^{12} \mathrm{~s}^{-1}$, respectively. Thus, at all temperatures passage through TS9 will be rate-limiting, and the corresponding rate constant for channel R7 is listed in Table 2.

There is also a possible singlet reaction path,

$$
\mathrm{CS}_{2}+\mathrm{O}_{2} \rightleftharpoons \mathrm{OCS}+{ }^{1} \mathrm{SO}
$$

Singlet oxygen can add to $\mathrm{CS}_{2}$ to make a singlet adduct with a four-membered ring. The high barrier for this step is consistent with the very low reactivity of $\mathrm{CS}_{2}$ toward $\mathrm{O}_{2}\left({ }^{1} \Delta\right) .{ }^{50}$ This adduct can also be accessed by $\mathrm{CS}_{2}+{ }^{3} \mathrm{O}_{2}$ via intersystem crossing. By application of the algorithm of Harvey, ${ }^{51}$ we have located a minimum-energy crossing point (MECP) that lies 81 $\mathrm{kJ} \mathrm{mol}^{-1}$, at the B3LYP/6-311G(2d,d,p) level of theory, above the singlet four-membered ring species. This places the MECP $\sim 145 \mathrm{~kJ} \mathrm{~mol}^{-1}$ above that for $\mathrm{CS}_{2}+\mathrm{O}_{2}$. Because the singlet four-membered ring is formed with more energy than necessary to overcome the barrier to OCS $+{ }^{1} \mathrm{SO}$, this dissociation will be fast and we adopt $145 \mathrm{~kJ} \mathrm{~mol}^{-1}$ as the activation energy for $\mathrm{CS}_{2}$ $+\mathrm{O}_{2} \rightleftharpoons \mathrm{OCS}+{ }^{1} \mathrm{SO}$. The $A$ factor incorporates the probability of intersystem crossing and is presumably smaller than a typical collision rate. We set it equal to the value measured for the spin-forbidden $\mathrm{O}+\mathrm{SO}_{2}$ addition, $3.6 \times 10^{11} \mathrm{~cm}^{3} \mathrm{~mol}^{-1} \mathrm{~s}^{-1} .52$ This is a crude estimate and might be uncertain perhaps by an order of magnitude.

Other singlet $\mathrm{CS}_{2} \mathrm{O}_{2}$ species, with five- and three-membered rings, have also been characterized. These have energies rather higher than the four-membered ring (Figure 5) and so probably play little role in the kinetics of the $\mathrm{CS}_{2}+\mathrm{O}_{2}$ reaction.

The activation energies calculated for channels R8, R12, R16, and R18 are probably accurate to within about $8 \mathrm{~kJ} \mathrm{~mol}^{-1}$. This corresponds to an uncertainty in the rate constant of about a factor of 3. For $k_{8}$ the uncertainty is larger, due to the crude estimate of the $A$-factor for this reaction.

Reaction Mechanism. The $\mathrm{CS}_{2}$ oxidation subset involves a number of other reactions, in addition to those characterized from $\mathrm{ab}$ initio calculations. The thermal dissociation of $\mathrm{CS}_{2}$,

$$
\mathrm{CS}_{2}(+\mathrm{M}) \rightleftharpoons \mathrm{CS}+\mathrm{S}(+\mathrm{M})
$$

has been investigated in high temperature shock tube experiments. ${ }^{25,55-64}$ In most of the earlier work, the decay of $\mathrm{CS}_{2}$ was monitored, ${ }^{58,60,62,63}$ whereas the more recent study of Murakami et al. ${ }^{25}$ involved measuring the time profile of $S$ atoms using atomic resonance spectroscopy. Direct extrapolation of the reported data yields rate constants at low temperature for the reverse step, $\mathrm{CS}+\mathrm{S}+\mathrm{M} \rightleftharpoons \mathrm{CS}_{2}+\mathrm{M}(\mathrm{R} 1)$, that are much too fast to be feasible. For this reason, Troe et al. $^{39}$ recently re-evaluated the available experimental data for thermal dissociation of $\mathrm{CS}_{2}$ to improve values for the lowpressure limit (based on refs 25, 58, 60, 61, 63, and 64) and the high-pressure limit (based on data from ref 62). We have adopted their recommended rate coefficients for (R1) that we believe to be reliable over a wider range of temperature and pressure than previous evaluations.

The reaction of $\mathrm{CS}_{2}$ with atomic hydrogen,

$$
\mathrm{CS}_{2}+\mathrm{H} \rightleftharpoons \mathrm{CS}+\mathrm{SH}
$$

has been studied by Woiki and Roth, ${ }^{65}$ who used time-resolved atomic resonance absorption spectroscopy (ARAS) measurements of $\mathrm{H}$ atoms in a shock tube to determine the rate constant. The reverse reaction of $\mathrm{CS}+\mathrm{SH}(\mathrm{R} 2)$ is exothermic and we expect it to proceed without a barrier. We include the reaction in the exothermic direction, deriving the rate constant $k_{2}=1.2 \times 10^{13} \mathrm{~cm}^{3} \mathrm{~mol}^{-1} \mathrm{~s}^{-1}$ from the measurements of Woiki and Roth of $k_{2 \mathrm{~b}}$ in the $1170-1830 \mathrm{~K}$ range.

Among reactions of $\mathrm{CS}_{2}$ with the $\mathrm{O} / \mathrm{H}$ radical pool, $\mathrm{CS}_{2}+\mathrm{O}$ is generally the most important. This reaction is known to have three product channels:

$$
\begin{aligned}
& \mathrm{CS}_{2}+\mathrm{O} \rightleftharpoons \mathrm{CS}+\mathrm{SO} \\
& \mathrm{CS}_{2}+\mathrm{O} \rightleftharpoons \mathrm{OCS}+\mathrm{S} \\
& \mathrm{CS}_{2}+\mathrm{O} \rightleftharpoons \mathrm{CO}+\mathrm{S}_{2}
\end{aligned}
$$

The main product channel is (R3), whereas channels R4 and R5 are minor, at least at low temperature. Data for the total reaction rate of $\mathrm{CS}_{2}+\mathrm{O}$ are in good agreement and are described well by the rate constant recommended by Singleton and Cvetanovic. ${ }^{66}$ Measurements of the product distribution at low temperatures indicate values of $k_{4} / k_{\text {tot }}$ of $8-10 \%{ }^{67-69}$ whereas $k_{5} / k_{\text {tot }}$ appears to be in the range $1-5 \% .^{67,69,70}$ Data for $k_{4} / k_{\text {tot }}$ in the $250-500 \mathrm{~K}$ range ${ }^{68}$ and at $1100 \mathrm{~K}^{71}$ indicate that the branching fraction decreases slightly with temperature but differences may be within experimental uncertainty. We assume that the branching fraction for $\mathrm{CS}_{2}+\mathrm{O}$ is independent of temperature and combine the overall rate constant from Singleton and Cvetanovic ${ }^{66}$ and the product distribution from the low temperature work ${ }^{67-69}$ to obtain values for $k_{3}, k_{4}$, and $k_{5}$.

On the basis of a theoretical study, $\mathrm{Saheb}^{72}$ recently concluded that channels R4 and R5 could both be disregarded, but this result is not supported by the experimental evidence. Saheb's work was focused on triplet stationary points on the $\mathrm{O}$ $+\mathrm{CS}_{2}$ potential energy surface, with correspondingly high barriers to the minor but crucial product channels OCS $+\mathrm{S}$ and $\mathrm{CO}+\mathrm{S}_{2}$, which led him to argue against a significant role for these pathways in $\mathrm{O}+\mathrm{CS}_{2}$ kinetics. Some 18 years earlier, Froese and Goddard ${ }^{73}$ investigated the possibilities of both singlet and triplet potential surfaces and commented on the possibility of intersystem crossing (ISC) between them. Our initial exploration at the B3LYP/6-311G(2d,d,p) level of density functional theory yields a minimum energy ISC point close to the geometry of cis-OSCS, $100 \mathrm{~kJ} \mathrm{~mol}^{-1}$ below that of $\mathrm{O}+\mathrm{CS}_{2}$. This opens the possibility that a small fraction of triplet $\mathrm{O}+\mathrm{CS}_{2}$ trajectories, having passed over a minor barrier, ${ }^{72}$ cross to the lower-lying singlet OSCS structure. This may undergo a series of rearrangements or dissociation via barriers that are significantly lower relative to the reactants than those on the triplet surface. ${ }^{73}$ Because the branching fraction for $\mathrm{CS}_{2}+\mathrm{O}$ is very important for the generation of chain carriers in $\mathrm{CS}_{2}$ oxidation, more work on this reaction is required.

The reaction of $\mathrm{CS}_{2}$ with $\mathrm{OH}$ is important in the atmosphere and has been studied at low temperatures, where it proceeds through addition:

$$
\mathrm{CS}_{2}+\mathrm{OH}(+\mathrm{M}) \rightleftharpoons \mathrm{HOCS}_{2}(+\mathrm{M})
$$

Because of the low thermal stability of $\mathrm{HOCS}_{2}$, redissociation of the adduct is fast even at low temperatures. We have adopted 
the recommendation of Atkinson et al. ${ }^{35}$ for the rate constant, but the value is not important for the modeling predictions in the present work. A possible secondary product channel for $\mathrm{CS}_{2}$ $+\mathrm{OH}$ to form $\mathrm{OCS}+\mathrm{SH}$ is apparently slow, with a measured upper limit of approximately $10^{9} \mathrm{~cm}^{3} \mathrm{~mol}^{-1} \mathrm{~s}^{-1}$ at $298 \mathrm{~K}^{35}$

The reaction of $\mathrm{CS}_{2}$ with atomic sulfur has two possible product channels:

$$
\begin{aligned}
& \mathrm{CS}_{2}+\mathrm{S}(+\mathrm{M}) \rightleftharpoons \mathrm{CS}_{3}(+\mathrm{M}) \\
& \mathrm{CS}_{2}+\mathrm{S} \rightleftharpoons \mathrm{CS}+\mathrm{S}_{2}
\end{aligned}
$$

Gao and Marshall ${ }^{36}$ investigated the reaction combining pulsed laser photolysis and resonance fluorescence over the temperature range 290-1040 K. Over 290-770 K, they observed pressure-dependent kinetics, which were attributed to the recombination channel R9. This is in agreement with the early reports of Basco and Pearson. ${ }^{74}$ At the intermediate temperatures of $690<T<770 \mathrm{~K}$, reaction $\mathrm{R} 9$ was reversible; i.e., the time scale for decomposition of $\mathrm{CS}_{3}$ to $\mathrm{CS}_{2}+\mathrm{S}$ was similar to that for addition. ${ }^{36}$ At $690-1040 \mathrm{~K}$, Gao and Marshall observed a change in mechanism to the pressureindependent channel R10. Their value of $k_{10}$ agrees well with the shock tube results of Woiki and Roth, ${ }^{75}$ obtained in the 1260-1820 K range. For both channels R9 and R10, we adopt the rate constants measured by Gao and Marshall. For the low pressure limit, we fit their data to an $A \cdot T^{\beta}$ expression to obtain a format that is compatible with CHEMKIN.

The reaction $\mathrm{CS}_{2}+\mathrm{SO}$ is not well characterized. Wood and Heicklen ${ }^{9}$ investigated the explosion limits of $\mathrm{CS}_{2} / \mathrm{O}_{2}$ mixtures at temperatures of $341-415 \mathrm{~K}$ and found that their results were sensitive to the competition between $\mathrm{CS}_{2}+\mathrm{O}_{2}$ and $\mathrm{CS}_{2}+\mathrm{SO}$, assuming the products of the latter reaction to be OCS $+\mathrm{S}_{2}$. We consider $\mathrm{S}$ abstraction to form $\mathrm{CS}$ and $\mathrm{S}_{2} \mathrm{O}$ to be more likely,

$$
\mathrm{CS}_{2}+\mathrm{SO} \rightleftharpoons \mathrm{CS}+\mathrm{S}_{2} \mathrm{O}
$$

and include this step with an estimated rate constant.

Among the reactions of $\mathrm{CS}$ with the $\mathrm{O} / \mathrm{H}$ radical pool, $\mathrm{CS}+$ $\mathrm{O}$ and $\mathrm{CS}+\mathrm{OH}$ are believed to be fast. The $\mathrm{CS}$ radical may recombine with atomic hydrogen to form HCS, but this step was not included in the present mechanism. The reaction of CS with atomic oxygen are expected to yield $\mathrm{CO}$ and $\mathrm{S}$ as the only products:

$$
\mathrm{CS}+\mathrm{O} \rightleftharpoons \mathrm{CO}+\mathrm{S}
$$

Only limited experimental investigations have been made to determine the rate expression of channel R13, but reported low-temperature data are in good agreement. ${ }^{67,76,77}$ The recommendations of Singleton and Cvetanovic ${ }^{66}$ and Atkinson et al. $^{35}$ for $k_{13}$ are based on the study by Lilenfeld and Richardson. ${ }^{77}$

There are no experimental data for the reaction of CS with $\mathrm{OH}$. Ab initio calculations $\mathrm{s}^{78,79}$ indicate that the reaction has no barrier, and Loison et al. ${ }^{40}$ report it to be fast, with OCS $+\mathrm{H}$ being the major product channel,

$$
\mathrm{CS}+\mathrm{OH} \rightleftharpoons \mathrm{OCS}+\mathrm{H}
$$

and a minor (20\%) contribution from formation of $\mathrm{CO}$ and $\mathrm{SH}$,

$$
\mathrm{CS}+\mathrm{OH} \rightleftharpoons \mathrm{CO}+\mathrm{SH}
$$

In addition to $\mathrm{CS}+\mathrm{SO}$ discussed above, Chernysheva et al. ${ }^{24}$ included reactions of CS with OCS and $\mathrm{SO}_{2}$,

$$
\begin{aligned}
& \mathrm{CS}+\mathrm{OCS} \rightleftharpoons \mathrm{CS}_{2}+\mathrm{CO} \\
& \mathrm{CS}+\mathrm{SO}_{2} \rightleftharpoons \mathrm{OCS}+\mathrm{SO}
\end{aligned}
$$

We consider these steps plausible and include them with estimated rate constants. However, with the current rate constants, which are considerably smaller than the values proposed by Chernysheva et al., they are too slow to influence modeling predictions.

Reactions of ozone have been proposed to play a role in chain termination at low temperatures for the $\mathrm{CS}_{2} / \mathrm{O}_{2}$ system. ${ }^{13,80,81}$ For this reason, we include an $\mathrm{O}_{3}$ reaction subset with rate constants from Atkinson et al. ${ }^{35}$ For the reaction of CS with $\mathrm{O}_{3}$, the rate constant was based on room temperature data ${ }^{35}$ and an assumed activation energy.

\section{RESULTS AND DISCUSSION}

Experimental results for oxidation of $\mathrm{CS}_{2}$ have been obtained in batch reactors, ${ }^{7-13}$ flow reactors, ${ }^{2,15}$ shock tubes, ${ }^{16-18}$ and laminar premixed flames. ${ }^{19-23}$ For evaluation of the model, we have selected experimental data obtained in batch and flow reactors, as well as in shock tubes. Most of the reported experiments were conducted under conditions with only trace amounts of water vapor. Clarke et al. ${ }^{2}$ conducted flow reactor experiments on $\mathrm{CS}_{2}$ conversion to $\mathrm{CO}$ and OCS in the presence of $\mathrm{H}_{2} \mathrm{O}, \mathrm{CO}_{2}$, and $\mathrm{SO}_{2}$. Unfortunately, the results reported for the $\mathrm{CS}_{2} / \mathrm{H}_{2} \mathrm{O}$ mixture were all obtained at close to full conversion of $\mathrm{CS}_{2}$ and these data were not used for model validation.

Explosion Limits and Low Temperature Induction Times. To evaluate the performance of the chemical kinetic model at low temperatures, predictions have been compared to measured explosion limits in batch reactors at temperatures between 350 and $520 \mathrm{~K}$. The experimental data were taken from Voronkov and Semenov, ${ }^{7}$ and Myerson and Taylor. ${ }^{8,14}$ These data sets were obtained in an overlapping temperature and pressure range but under conditions of low $\left(300 \mathrm{ppm}^{7}\right)$ and high $\left(25 \%^{8,14}\right)$ concentrations of $\mathrm{CS}_{2}$, respectively.

Figure 6 compares the measured and calculated explosion limits. Both sets of explosion limits exhibit the characteristic peninsula-shape, involving a lower as well as an upper limiting pressure in a certain temperature range. Batch reactor results for $\mathrm{CS}_{2}$ oxidation have been reported to depend on the surface

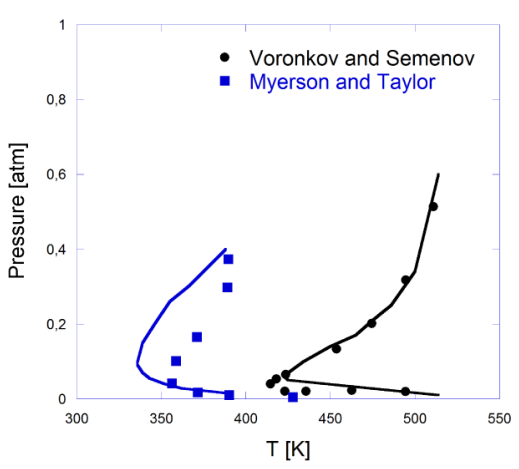

Figure 6. Comparison of experimental and predicted explosion limits for $\mathrm{CS}_{2}$ in a batch reactor. The experimental data are taken from Voronkov and Semenov ${ }^{7}$ and Myerson and Taylor. ${ }^{8,14}$ The symbols mark experimental data, and solid lines denote model predictions. Inlet composition for Voronkov and Semenov experiments: $300 \mathrm{ppm}$ of $\mathrm{CS}_{2}, 21 \% \mathrm{O}_{2}$, and $79 \% \mathrm{~N}_{2}$. Inlet composition for Myerson and Taylor experiments: $25 \% \mathrm{CS}_{2}$ and $75 \% \mathrm{O}_{2}$. 
to volume ratio of the reactor ${ }^{8,9,14}$ and the first (lower) explosion limit is controlled mainly by competition between a gas-phase chain branching reaction sequence and termination of radicals at the wall of the reactor. In the modeling, we did not include a wall termination reaction; instead explosion had to occur within a set induction time to be acknowledged. The limiting induction time was somewhat arbitrarily set to $10 \mathrm{~s}$; the use of a different value would affect the predicted explosion limits but not the overall trends.

The experimental results indicate that the lower explosion limit is only slightly dependent on temperature, whereas the upper limit exhibits a stronger temperature dependence. Similar to the first limit, the second limit is controlled by a competition between chain branching and chain terminating reactions, but the second limit is expected to be independent of surface reactions.

The agreement between the reported observations and the calculations is very good, in particular for the dilute mixture of Voronkov and Semenov. ${ }^{7}$ The model predicts correctly that the lower limit pressure at which explosion occurs has only a small dependence on temperature in the investigated range and it captures well the secondary explosion limits for both mixtures. Also the low temperature limits for explosion, which according to the reported data are approximately 350 and $410 \mathrm{~K}$, respectively, are predicted satisfactorily.

Induction times for the $\mathrm{CS}_{2} / \mathrm{O}_{2}$ system at low temperatures have been reported by several groups. ${ }^{9,11,14}$ Depending on temperature, pressure, and mixture composition, the time for ignition may vary from a few seconds to several minutes. For model validation purposes, the shorter induction time data are preferable, as they are less prone to be affected by loss of radicals on the reactor walls. Figure 7 compares the induction

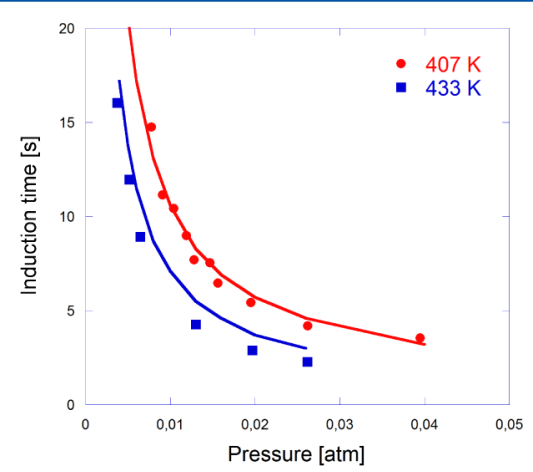

Figure 7. Comparison of experimental and predicted induction times as a function of pressure and temperature for $\mathrm{CS}_{2}$ in a batch reactor. The experimental data are taken from Taylor and Myerson. ${ }^{14}$ The symbols mark experimental data, and solid lines denote model predictions. Inlet composition: $25 \% \mathrm{CS}_{2}$ and $75 \% \mathrm{O}_{2}$.

times reported by Taylor and Myerson ${ }^{14}$ for a mixture of $25 \%$ $\mathrm{CS}_{2}$ and $75 \% \mathrm{O}_{2}$ at temperatures of 407 and $433 \mathrm{~K}$ and varying pressure with modeling predictions. Again, the agreement between observed and calculated data is good, indicating that the low temperature chain branching chemistry of $\mathrm{CS}_{2}$ under oxidizing conditions is described well by the model.

Oxidation in a Flow Reactor. Homann et al. ${ }^{15}$ reported detailed species measurements as a function of time (distance) from oxidation of $\mathrm{CS}_{2}$ in a low-pressure flow reactor. The data were obtained by molecular beam mass spectrometry. Homann et al. measured concentrations of $\mathrm{CS}_{2}, \mathrm{OCS}, \mathrm{CO}, \mathrm{CO}_{2}, \mathrm{SO}$, and $\mathrm{SO}_{2}$, as well as a number of minor species, at a pressure of
$0.0395 \mathrm{~atm}$ and temperatures of 1200 and $1360 \mathrm{~K}$, respectively. For the purpose of evaluating the model, we have chosen the $1200 \mathrm{~K}$ data, which were obtained at more dilute and wellcontrolled conditions. The $1360 \mathrm{~K}$ experiments were conducted with 4 times higher $\mathrm{CS}_{2}$ inlet concentrations, resulting in an adiabatic temperature increase for complete oxidation of several hundred degrees.

The experimental results are compared with modeling predictions in Figure 8. In addition to the sulfur species

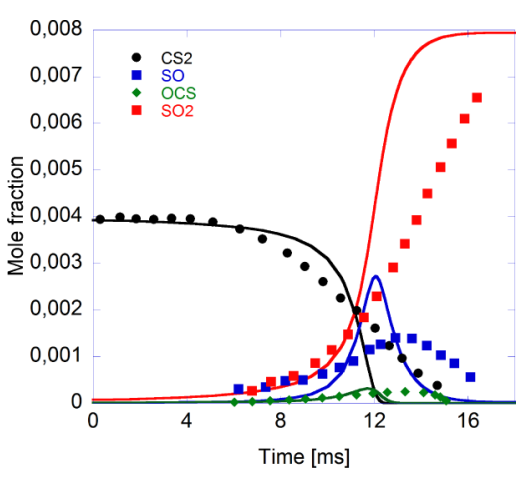

Figure 8. Comparison of experimental and predicted mole fractions for oxidation of $\mathrm{CS}_{2}$ in a flow reactor at low pressure. The experimental data are taken from Homann et al. ${ }^{15}$ The symbols mark experimental data, and solid lines denote model predictions. Modeling predictions are shifted $39 \mathrm{~ms}$ to match the experimental time for $50 \%$ conversion of $\mathrm{CS}_{2}$. Conditions: $T=1200 \mathrm{~K}, P=0.0395$ atm, inlet composition is $0.4 \% \mathrm{CS}_{2}, 8.0 \% \mathrm{O}_{2}$, balance Ar.

shown, also $\mathrm{S}, \mathrm{S}_{2}, \mathrm{~S}_{2} \mathrm{O}$, and $\mathrm{S}_{2} \mathrm{O}_{2}$ were detected in small quantities. The measured induction time (about $8 \mathrm{~ms}$ ) is significantly shorter than the calculated value; the predicted profiles have been shifted approximately $40 \mathrm{~ms}$ to lower values to match the observed time for $50 \%$ conversion of $\mathrm{CS}_{2}$. Once reaction has started, the model predicts a consumption rate for $\mathrm{CS}_{2}$, which is faster than observed. The overprediction of the oxidation rate for $\mathrm{CS}_{2}$ after onset of reaction, facilitated by a sequence of chain-branching reactions discussed below, has the consequence that also the peaks of SO and OCS become too narrow, and the $\mathrm{SO}_{2}$ formation rate is larger than observed. The maximum concentration of $\mathrm{SO}$ is predicted within a factor of 2 , whereas the peak concentration of OCS is calculated quite accurately.

Both Homann et al. $^{15}$ and Howgate and Barr, ${ }^{20}$ who previously modeled these data, pointed out that the observed induction time in the flow reactor was possibly affected by experimental artifacts. In the experiments, the reactants $\mathrm{CS}_{2}$ and $\mathrm{O}_{2}$ were preheated separately and mixed at the entrance to the reaction zone. Atomic oxygen, formed from $\mathrm{O}_{2}$ at the heating elements in the preheating oven, was suggested to promote onset of reaction. Also, the induction time could conceivably be affected by the mixing process at the reaction zone inlet and/or by reactions at the reactor surface, facilitated by fast diffusion to the wall at the low pressure. However, it is noteworthy that in their modeling of OCS oxidation in the same reactor setup, Glarborg and Marshall ${ }^{26}$ found no indication that the induction time was affected by experimental artifacts.

The oxidation rate of $\mathrm{CS}_{2}$ upon initiation of reaction was modeled satisfactorily by both Homann et al. and Howgate and Barr. They obtained a slower oxidation rate than in the present work by introducing loss of atomic oxygen on the reactor 
surface and by using a fast rate constant for $\mathrm{CS}_{2}+\mathrm{S}$ to yield $\mathrm{CS}$ $+\mathrm{S}_{2}$; a value that is not supported by more recent direct measurements. ${ }^{36,75}$ Some loss of oxygen atoms through a heterogeneous reaction at the reactor wall is plausible; however, such a reaction was not taken into consideration in the present modeling.

Oxidation in a Shock Tube. $\mathrm{CS}_{2}$ ignition and oxidation have been investigated in shock tubes at high temperature. ${ }^{16-18}$ We believe that the most reliable data are those of Saito et al., ${ }^{18}$ who used very dilute mixtures and monitored the concentration of atomic oxygen by ARAS. Figure 9 compares experimental

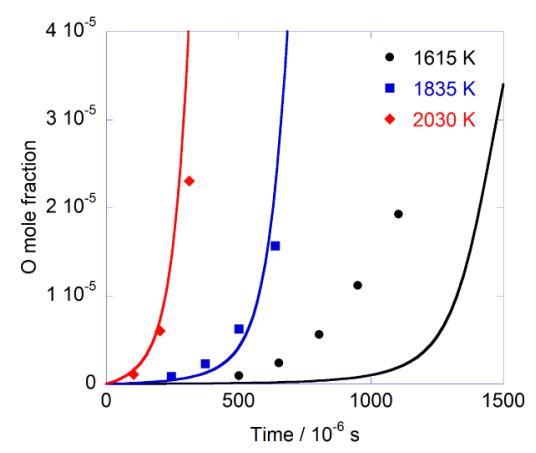

Figure 9. Comparison of experimental and predicted mole fractions of atomic oxygen for oxidation of $\mathrm{CS}_{2}$ in a shock tube. The experimental data are taken from Saito et al. ${ }^{18}$ The symbols mark experimental data, and solid lines denote model predictions. Conditions: $T=1615,1835$, and $2035 \mathrm{~K}$. The total concentration $[\mathrm{M}]=1.8 \times 10^{-5} \mathrm{~mol} \mathrm{~cm}^{-3}$. The inlet composition is $50 \mathrm{ppm}$ of $\mathrm{CS}_{2}, 0.2 \% \mathrm{O}_{2}(1615 \mathrm{~K})$ or $100 \mathrm{ppm}$ of $\mathrm{CS}_{2}, 0.1 \% \mathrm{O}_{2}(1835$ and $2030 \mathrm{~K})$; balance $\mathrm{Ar}$.

and predicted concentrations of $\mathrm{O}$ as a function of time at three selected temperatures $(1615,1835$, and $2030 \mathrm{~K})$. In the calculations the total concentration $[\mathrm{M}]$ is assumed to be $1.8 \times$ $10^{-5} \mathrm{~mol} \mathrm{~cm}{ }^{-3}$, similar to other $\mathrm{CS}_{2}$ oxidation experiments reported in the paper. However, neither the gas density nor the pressure was reported by Saito et al. for the data sets chosen for analysis in the present work and this introduces an uncertainty in the modeling interpretation.

The comparison in Figure 9 shows that the $\mathrm{O}$ atom profiles are predicted accurately at the higher temperatures, 1835 and $2030 \mathrm{~K}$. However, at $1615 \mathrm{~K}$ both the induction time for $\mathrm{CS}_{2}$ and the formation rate of $[\mathrm{O}]$ upon ignition are overpredicted. This discrepancy is similar to the one discussed above for the flow reactor results of Homann et al. at $1200 \mathrm{~K}$. It indicates that the balance between initiation and chain branching in the model at higher temperatures is not correct. This is discussed in more detail in the next section.

Reaction Paths and Bottlenecks. In this section, we discuss the oxidation pathways for $\mathrm{CS}_{2}$ and identify the reactions that are rate limiting for the oxidation rate. Figure 10 shows the results of a sensitivity analysis for selected experimental conditions. Table 3 provides an uncertainty estimate for the rate constants of the key reactions.

Analysis of the calculations with the model shows that roughly the same set of key reactions plays an important role over the range of conditions investigated, from the low temperature batch reactor experiments to the high temperature shock tube experiments. Reaction is initiated by thermal dissociation of $\mathrm{CS}_{2}$,

$$
\mathrm{CS}_{2}(+\mathrm{M}) \rightleftharpoons \mathrm{CS}+\mathrm{S}(+\mathrm{M})
$$

or by reaction of $\mathrm{CS}_{2}$ with $\mathrm{O}_{2}$,

$$
\mathrm{CS}_{2}+\mathrm{O}_{2} \rightleftharpoons \mathrm{OCS}+{ }^{1} \mathrm{SO}
$$

After initiation, the generation of chain carriers in the system is controlled by the competition between chain branching and chain terminating reaction sequences. Sequence A,

$$
\begin{aligned}
& \mathrm{CS}_{2}+\mathrm{O} \rightleftharpoons \mathrm{CS}+\mathrm{SO} \\
& \mathrm{SO}+\mathrm{O}_{2} \rightleftharpoons \mathrm{SO}_{2}+\mathrm{O} \\
& \overline{\mathrm{CS}_{2}+\mathrm{O}_{2} \rightleftharpoons \mathrm{CS}+\mathrm{SO}_{2}}
\end{aligned}
$$

is chain propagating at low to medium temperatures where the CS radical is comparatively unreactive toward stable species. At high temperatures, CS may react with $\mathrm{O}_{2}$ to yield atomic oxygen R16 and (A) becomes chain branching. Sequence B,

$$
\begin{aligned}
& \mathrm{CS}_{2}+\mathrm{O} \rightleftharpoons \mathrm{OCS}+\mathrm{S} \\
& \mathrm{S}+\mathrm{O}_{2} \rightleftharpoons \mathrm{SO}+\mathrm{O} \\
& \mathrm{SO}+\mathrm{O}_{2} \rightleftharpoons \mathrm{SO}_{2}+\mathrm{O} \\
& \mathrm{CS}_{2}+2 \mathrm{O}_{2} \rightleftharpoons \mathrm{OCS}+\mathrm{SO}_{2}+\mathrm{O}
\end{aligned}
$$

is a chain branching sequence. The propagating and branching sequences compete with terminating steps, mainly the reaction

$$
\mathrm{CS}_{2}+\mathrm{O} \rightleftharpoons \mathrm{CO}+\mathrm{S}_{2}
$$

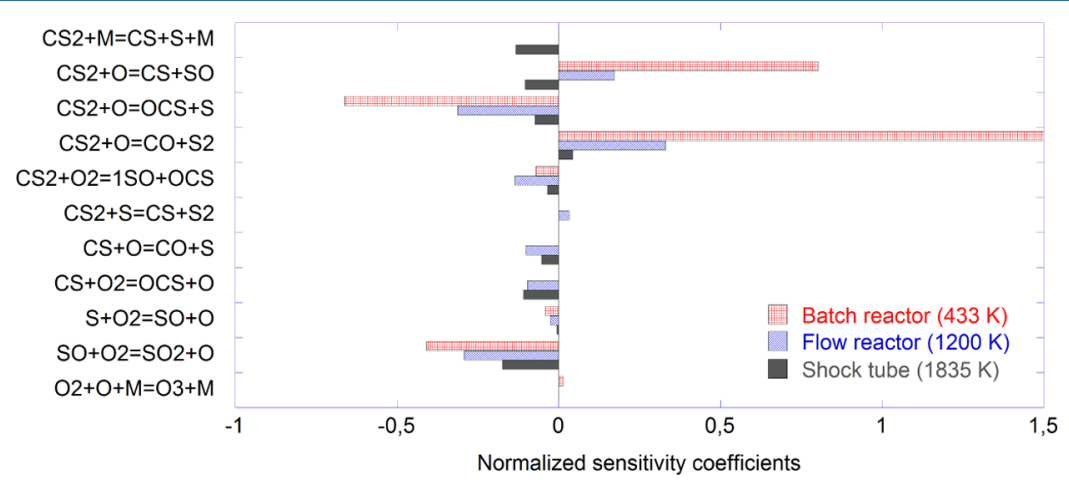

Figure 10. Sensitivity coefficients for the induction time at different reaction conditions. The coefficients show the relative change in the predicted induction time caused by a factor of 2 increase in the rate constant of the specific reaction. Conditions correspond to those of the experiments conducted in batch reactor (Figure 7, $433 \mathrm{~K}, 0.01 \mathrm{~atm}$ ), flow reactor (Figure 8, $1200 \mathrm{~K}, 0.0395 \mathrm{~atm}$ ), and shock tube (Figure 9, $1835 \mathrm{~K}, 2.9 \mathrm{~atm})$. 
Table 3. Uncertainty Evaluation for Key Reactions in the $\mathrm{CS}_{2}$ Oxidation Subset

\begin{tabular}{|c|c|c|c|c|}
\hline \multicolumn{2}{|r|}{ reaction } & method $^{a}$ & uncertainty $^{b}$ & commen \\
\hline \multirow[t]{3}{*}{1.} & $\mathrm{CS}+\mathrm{S}(+\mathrm{M}) \rightleftharpoons \mathrm{CS}_{2}(+\mathrm{M})$ & & & \\
\hline & high pressure limit $k_{\infty}$ : & review, theory & $\mathrm{UF}=3(300-2000 \mathrm{~K})$ & $c$ \\
\hline & low pressure limit $k_{0}$ : & review, theory & $\mathrm{UF}=2(300-2000 \mathrm{~K})$ & $c$ \\
\hline $3-5$ & $\mathrm{CS}_{2}+\mathrm{O} \rightleftharpoons$ products & review & $\mathrm{UF}=1.5(218-920 \mathrm{~K})$ & $d$ \\
\hline 3. & $\mathrm{CS}_{2}+\mathrm{O} \rightleftharpoons \mathrm{CS}+\mathrm{SO}$ & review & $\mathrm{UF}=1.5(218-920 \mathrm{~K})$ & $d$ \\
\hline 4. & $\mathrm{CS}_{2}+\mathrm{O} \rightleftharpoons \mathrm{OCS}+\mathrm{S}$ & review & $\mathrm{UF}=2(250-500 \mathrm{~K})$ & $d, e$ \\
\hline 5. & $\mathrm{CS}_{2}+\mathrm{O} \rightleftharpoons \mathrm{CO}+\mathrm{S}_{2}$ & review & $\mathrm{UF}=3(298 \mathrm{~K})$ & $d, e$ \\
\hline 8. & $\mathrm{CS}_{2}+\mathrm{O}_{2} \rightleftharpoons \mathrm{OCS}+{ }^{1} \mathrm{SO}$ & theory & $\mathrm{UF}=10$ & $f$ \\
\hline 13. & $\mathrm{CS}+\mathrm{O} \rightleftharpoons \mathrm{CO}+\mathrm{S}$ & review & $\mathrm{UF}=1.25(150-300 \mathrm{~K})$ & $g$ \\
\hline 16. & $\mathrm{CS}+\mathrm{O}_{2} \rightleftharpoons \mathrm{OCS}+\mathrm{O}$ & theory & $\mathrm{UF}=3(1000 \mathrm{~K})$ & $h$ \\
\hline
\end{tabular}

${ }^{a}$ Method of deriving the rate constant used in the present mechanism. ${ }^{b}$ The uncertainty is given as an uncertainty factor (UF). ${ }^{c}$ Uncertainty evaluation from ref 39. ${ }^{d}$ Uncertainty evaluation from ref $66 .{ }^{e}$ The branching fraction for the $\mathrm{CS}_{2}+\mathrm{O}$ reaction has only been measured directly at low temperature, and the uncertainty increases with temperature. ${ }^{{ }}$The factor of 10 uncertainty in the rate constant relates to the difficulty of calculating the $A$-factor for a spin-forbidden reaction. In addition there is a $\pm 8 \mathrm{~kJ} \mathrm{~mol}^{-1}$ uncertainty in the activation energy. ${ }^{g}$ Uncertainty evaluation from ref 35 . The reaction is fast, and the uncertainty factor is not expected to increase above 2 with temperature. ${ }^{h}$ The uncertainty relates to a $\pm 8 \mathrm{~kJ}$ mol ${ }^{-1}$ uncertainty in the activation energy.

Other termination steps may also be active, dependent on the type of reactor and the temperature/pressure range of the experiment.

The chemistry responsible for the $\mathrm{CS}_{2}$ explosion limits has been discussed in a series of papers by Azatyan and coworkers. ${ }^{13,80,81}$ Their findings are largely in agreement with the present analysis. Under the conditions of the batch reactor experiments $(350-520 \mathrm{~K})$, the $\mathrm{CS}_{2}+\mathrm{O}_{2}$ reaction $\mathrm{R} 8$ is the initiating step. The ignition delay and explosion limits are controlled by the competition of the chain branching sequence (B), which promotes reaction, and the terminating reaction R5. Under these conditions, sequence $A$ acts in effect as a terminating sequence, with positive sensitivity coefficients for reaction R3. Some additional termination steps may be active, depending on the pressure. At the lower limiting pressure, termination is dominated by radical diffusion to the wall and subsequent deactivation:

$$
\mathrm{O} \stackrel{\text { +wall }}{\longrightarrow} \text { inert }
$$

At increased pressure, the second explosion limit is controlled by (R5), together with the gas-phase termination sequence:

$$
\begin{aligned}
& \mathrm{O}_{2}+\mathrm{O}+\mathrm{M} \rightleftharpoons \mathrm{O}_{3}+\mathrm{M} \\
& \mathrm{O}_{3}+\mathrm{O} \rightleftharpoons \mathrm{O}_{2}+\mathrm{O}_{2}
\end{aligned}
$$

Only the first of these steps, the $\mathrm{O}_{2}+\mathrm{O}$ recombination, shows up in the sensitivity analysis, as the $\mathrm{O}_{3}+\mathrm{O}$ reaction is fast. Reactions of $\mathrm{S}$ and SO with $\mathrm{CS}_{2}$ (R9)-(R11) could act as chain terminating steps, but under the investigated conditions, they cannot compete with $\mathrm{S}+\mathrm{O}_{2}$ and $\mathrm{SO}+\mathrm{O}_{2}$.

The predicted ignition delay times and explosion limits depend strongly on the product branching fraction of the $\mathrm{CS}_{2}+$ $\mathrm{O}$ reactions $\mathrm{R} 3, \mathrm{R} 4$, and $\mathrm{R} 5$. The good agreement between experimental results and modeling predictions support the accuracy of the low temperature measurements of the relative importance of channels R4 and R5. ${ }^{67-69}$ As pointed out by Azatyan et al., ${ }^{81}$ reaction $\mathrm{R} 4$ is required to supply the necessary chain branching; without this step the $\mathrm{CS}_{2} / \mathrm{O}_{2}$ system would be nonexplosive at these temperatures.

For the flow reactor conditions (Figure 8), both the initiation reaction $\left(\mathrm{CS}_{2}+\mathrm{O}_{2}\right)$ and the mechanisms of radical formation and termination are similar to those of the batch reactor experiments. The chain branching sequence (B) competes with the propagating sequence $(A)$ and the terminating reaction (R5). At the elevated temperature $(1200 \mathrm{~K})$ and increased radical levels, also reactions of CS with $\mathrm{O}(\mathrm{R} 13)$ and $\mathrm{O}_{2}(\mathrm{R} 16)$ act to promote oxidation, whereas $\mathrm{CS}_{2}+\mathrm{S}$ reaction $\mathrm{R} 10$ inhibits oxidation.

Under the conditions of the high temperature shock tube experiments, thermal dissociation of $\mathrm{CS}_{2}(\mathrm{R} 1 \mathrm{~b})$ becomes the most important initiation step. The $\mathrm{CS}+\mathrm{O}_{2}$ reaction (R16) is here sufficiently fast to contribute to radical generation, causing sequence A to become chain branching, along with sequence B. Reaction R5 is still the controlling terminating step.

The results of Figures 6-9 indicate that the modeling predictions are most accurate at low temperatures where calculated ignition delays and explosion limits are in good agreement with observed values. The predictive capability of the model under these conditions is facilitated by the knowledge of the low temperature branching fraction for $\mathrm{CS}_{2}$ $+\mathrm{O}$. At the higher temperatures of the flow reactor and shock tube experiments, the model appears to overpredict both the induction time for $\mathrm{CS}_{2}$ and the formation rate of [O] upon ignition. As discussed above, this indicates that the balance between initiation and chain branching in the model at higher temperatures is not correct. The rate constant for $\mathrm{CS}_{2}+\mathrm{O}_{2} \mathrm{R} 8$, which is a major initiation step, is quite uncertain because the reaction involves intersystem crossing from the triplet to the singlet surface. Also the $\mathrm{CS}_{2}+\mathrm{O}$ branching fraction, which is controlling the chain branching rate, is quite uncertain at elevated temperatures. It is unlikely, as assumed in the model, that the branching fraction is independent of temperature. Available data in the $250-500 \mathrm{~K}$ range ${ }^{68}$ and at $1100 \mathrm{~K}^{71}$ indicate that the $k_{4} / k_{\text {tot }}$ ratio decreases slightly with temperature. This would slow down the predicted formation rate of atomic oxygen, consistent with the high temperature results, but more work is needed to confirm this.

\section{CONCLUSIONS}

A detailed chemical kinetic model for oxidation of $\mathrm{CS}_{2}$ has been developed and evaluated against experimental results from batch reactors, flow reactors, and shock tubes. Rate constants and product channels for a number of key reactions, i.e., $\mathrm{CS}_{2}+$ $\mathrm{O}_{2}, \mathrm{CS}_{2}+\mathrm{SO}_{2}, \mathrm{CS}+\mathrm{O}_{2}$, and $\mathrm{CS}+\mathrm{SO}$, were determined through ab initio calculations. The $\mathrm{CS}_{2}+\mathrm{O}_{2}$ reaction forms 
OCS $+\mathrm{SO}$, with the lowest energy barrier involving crossing from the triplet to the singlet surface. For $\mathrm{CS}+\mathrm{O}_{2}$, which yields $\mathrm{OCS}+\mathrm{O}$, we found a high barrier to reaction, causing this step to be important only at elevated temperatures. The model predicts low temperature ignition delays and explosion limits quite accurately, whereas at higher temperatures the model appears to overpredict both the induction time for $\mathrm{CS}_{2}$ oxidation and the formation rate of [O] upon ignition. The predictive capability of the model depends on the accuracy of the rate constant for the initiation step $\mathrm{CS}_{2}+\mathrm{O}_{2}$, which is difficult to calculate due to the intersystem crossing, and the branching fraction for $\mathrm{CS}_{2}+\mathrm{O}$, which is measured only at low temperatures. More work on these important reactions is desirable.

\section{ASSOCIATED CONTENT}

\section{S Supporting Information}

Computed results for stationary points on the potential energy surfaces for the reactions $\mathrm{CS}+\mathrm{O}_{2}, \mathrm{CS}+\mathrm{SO}, \mathrm{CS}_{2}+\mathrm{SO}_{2}$, and $\mathrm{CS}_{2}+\mathrm{O}_{2}$ (geometries, rotational constants, frequencies, and energies) at the W1U or CBS-QB3 levels of theory. Thermodynamic data and reaction mechanism in Chemkin input format. This material is available free of charge via the Internet at http://pubs.acs.org

\section{AUTHOR INFORMATION}

\section{Notes}

The authors declare no competing financial interest.

\section{ACKNOWLEDGMENTS}

The authors thank Dave Golden for helpful comments. P.M. thanks the R. A. Welch Foundation (Grant B-1174) for support and the National Science Foundation (Grant CHE-0741936) for purchase of computational facilities.

\section{REFERENCES}

(1) Monnery, W. D.; Svreck, W. Y.; Behie, L. A. Modeling the Modified Claus Process Reaction Furnace and the Implications on Plant-Design and Recovery. Can. J. Chem. Eng. 1993, 71, 711-724.

(2) Clark, P. D.; Dowling, N. I.; Huang, M.; Svreck, W. Y.; Monnery, W. D. Mechanisms of $\mathrm{CO}$ and COS Formation in the Claus Furnace. Ind. Eng. Chem. Res. 2001, 40, 497-508.

(3) Gargurevich, I. A. Hydrogen Sulfide Combustion: Relevant Issues under Claus Furnace Conditions. Ind. Eng. Chem. Res. 2005, 44, 77067729.

(4) Laursen, J. K.; Jensen, F. E. WSA - Meeting Industry Demands. Sulphur 2007, September - October, 80-85.

(5) Xie, W.; Chang, L.; Wang, D.; Xie, K.; Wall, T.; Yu, J. Removal of Sulfur at High Temperatures using Iron-based Sorbents Supported on Fine Coal Ash. Fuel 2010, 89, 868-873.

(6) Meng, X.; de Jong, W.; Pal, R.; Verkooijen, A. H. M. In Bed and Downstream Hot Gas Desulphurization during Solid Fuel Gasification: A review. Fuel Process. Technol. 2010, 91, 964-981.

(7) Voronkov, V. G.; Semenov, N. N. Zh. Fiz. Khim. 1939, 13, 1695.

(8) Myerson, A. L.; Taylor, F. R. The Ignition Limits of 1-3 Mixtures of Carnon Disulfide and Oxygen. J. Am. Chem. Soc. 1953, 75, 4348-4350.

(9) Wood, W. P.; Heicklen, J. Kinetics and Mechanism of the Carbon Disulfide - Oxygen Explosion. J. Phys. Chem. 1971, 75, 861-866.

(10) Gordon, E. B.; Drozdov, M. S.; Shatrov, V. D.; Tal'roze, V. L. Fiz. Goreniya Vzryva 1974, 10, 11-16.

(11) Gordon, E. B.; Drozdov, M. S. Spectroscopic Studies of the Explosion of Mixtures of $\mathrm{CS}_{2}$ and $\mathrm{O}_{2}$. Combust. Explosion Shock Waves 1980, 16, 185-189.
(12) Dudkin, V. A. Lower Self Ignition Limit of $\mathrm{CS}_{2}-\mathrm{O}_{2}$ Mixtures. Combust. Explosion Shock Waves 1982, 18, 607-609.

(13) Azatyan, V. V.; Shestakov, A. F. $\mathrm{CS}_{2}+\mathrm{O}_{2}$ Self-Ignition and the Activated Complex in Its Rate-Limiting Step. Kinet. Catal. 2008, 49, 616-620.

(14) Taylor, F. R; Myerson, A. L. First Limit Induction Time Studies of $\mathrm{CS}_{2}-\mathrm{O}_{2}$ Explosions. Proc. Combust. Symp. 1958, 7, 72-79.

(15) Homann, K. H.; Krome, G.; Wagner, H. G. Carbon Disulfide Oxidation. 3. Isothermic Oxidation of Isothermic Oxidation of Carbon Disulfide. Ber. Bunsen-Ges. Phys. Chem. 1970, 74, 654-659.

(16) Sheen, D. B. Shock Tube Study of the Oxidation of Carbon Disulfide. J. Phys. Chem. 1970, 52, 648-655.

(17) Hardy, J.; Gardiner, W. C., Jr. Shock Tube Study of Carbon Disulfide Oxidation. Proc. Combust. Inst. 1977, 16, 985-995.

(18) Saito, K.; Ueda, Y.; Ito, R.; Kakumoto, T.; Imamura, A. Measurements of the Bimolecular Rate Constants for $\mathrm{S}+\mathrm{O}_{2} \rightarrow \mathrm{SO}+\mathrm{O}$ and $\mathrm{CS}_{2}+\mathrm{O}_{2} \rightarrow \mathrm{CS}+\mathrm{SO}_{2}$ at High Temperatures. Int. J. Chem. Kinet. 1986, 18, 871-884.

(19) Suart, R. D.; Dawson, P. H.; Kimbell, G. H. $\mathrm{CS}_{2} / \mathrm{O}_{2}$ Chemical Lasers - Chemistry and Performance Characteristics. J. Appl. Phys. 1972, 43, 1022-1032.

(20) Howgate, D. W.; Barr, T. A. Dynamics of the $\mathrm{CS}_{2}-\mathrm{O}_{2}$ Flame. J. Chem. Phys. 1973, 59, 2815-2829.

(21) Richardson, R. J. CS-O $\mathrm{O}_{2}$ Flame Reaction Chemistry. J. Phys. Chem. 1975, 79, 1153-1158.

(22) Vetter, A. A.; Culick, F. E. C. Flame Speed of a Low-Pressure $\mathrm{CS}_{2}-\mathrm{O}_{2}$ Flame. Combust. Flame 1977, 30, 107-109.

(23) Vetter, A. A.; Culick, F. E. C. Thermal Theory Approximation to a Low-Pressure $\mathrm{CS}_{2}-\mathrm{O}_{2}$ Flame. Combust. Flame 1978, 33, 169-177.

(24) Chernysheva, A. V.; Basevich, V. Y.; Vedeneev, V. I.; Arutyunov, V. S. Mechanism of the Ga-Phase Oxidation of Carbon Disulfide at Elevated Temperatures (the C-S.O System). Russ. Chem. B 1992, 41, 629-637.

(25) Murakami, Y.; Kosugi, M.; Susa, K.; Kobayashi, T.; Fujii, N. Kinetics and Mechanism for the Oxidation of $\mathrm{CS}_{2}$ and $\mathrm{COS}$ at High Temperatures. Bull. Chem. Soc. JPN 2001, 74, 1233-1240.

(26) Glarborg, P.; Marshall, P. Oxidation of Reduced Sulfur Species: Carbonyl Sulfide. Int. J. Chem. Kinet. 2013, 45, 429-439.

(27) Rasmussen, C. L.; Hansen, J.; Marshall, P.; Glarborg, P. Experimental Measurements and Kinetic Modeling of $\mathrm{CO} / \mathrm{H}_{2} / \mathrm{O}_{2} /$ NOx Conversion at High Pressure. Int. J. Chem. Kinet. 2008, 40, 454480.

(28) Hashemi, H.; Christensen, J. M.; Gersen, S.; Glarborg, P. Hydrogen Oxidation at High Pressure and Intermediate Temperatures: Experiments and Kinetic Modeling. Proc. Combust. Inst. 2014, DOI: $10.1016 /$ j.proci.2014.05.101.

(29) Dagaut, P.; Lecomte, F.; Mieritz, J.; Glarborg, P. Experimental and Kinetic Modeling Study of the Effect of $\mathrm{NO}$ and $\mathrm{SO}_{2}$ on the Oxidation of CO- $\mathrm{H}_{2}$ Mixtures. Int. J. Chem. Kinet. 2003, 35, 564-575.

(30) Glarborg, P. Hidden Interactions - Trace Species Governing Combustion and Emissions. Proc. Combust. Inst. 2007, 31, 77-98.

(31) Rasmussen, C. L.; Glarborg, P.; Marshall, P. Mechanisms of Radical Removal by $\mathrm{SO}_{2}$. Proc. Combust. Inst. 2007, 31, 339-347.

(32) Jørgensen, T. L.; Livbjerg, H.; Glarborg, P. Homogeneous and Heterogeneously Catalyzed Oxidation of $\mathrm{SO}_{2}$. Chem. Eng. Sci. 2007, 62, 4496-4499.

(33) Hindiyarti, L.; Glarborg, P.; Marshall, P. Reactions of $\mathrm{SO}_{3}$ with the O/H Radical Pool under Combustion Conditions. J. Phys. Chem. A 2007, 111, 3984-3991.

(34) Zhou, C.; Sendt, K.; Haynes, B. Experimental and Kinetic Modelling Study of $\mathrm{H}_{2} \mathrm{~S}$ Oxidation. Proc. Combust. Inst. 2013, 34, 625632.

(35) Atkinson, R.; Baulch, D. L.; Cox, R. A.; Crowley, J. N.; Hampson, R. F.; Hynes, R. G.; Jenkin, M. E.; Rossi, M. J.; Troe, J. Evaluated kinetic and photochemical data for atmospheric chemistry: Volume I - gas phase reactions of $\mathrm{O}_{x}, \mathrm{HO}_{x}, \mathrm{NO}_{\mathrm{x}}$ and $\mathrm{SO}_{\mathrm{x}}$ species. Atmos. Chem. Phys. 2004, 4, 1461-1738. 
(36) Gao, Y.; Marshall, P. An Experimental and Computational Study of the Reaction of Ground-State Sulfur Atoms with Carbon Disulfide. J. Chem. Phys. 2011, 135, 144306.

(37) Goos, E.; Burcat, A.; Ruscic, B. Ideal gas thermochemical database with updates from active thermochemical tables (ftp://ftp. technion.ac.il/pub/supported/aetdd/thermodynamics mirrored at http://garfield.chem.elte.hu/burcat/burcat.html).

(38) Lu, C.-W.; Wu, Y.-J.; Lee, Y.-P.; Zhu, R. S.; Lin, M. C. Experimental and theoretical investigation of rate coefficients of the reaction $\mathrm{S}\left({ }^{3} \mathrm{P}\right)+\mathrm{OCS}$ in the temperature range of $298-985 \mathrm{~K}$. J. Chem. Phys. 2006, 125, 164329.

(39) Troe, J.; Marshall, P.; Glarborg, P. Manuscript in preparation (2013).

(40) Loison, J.-C.; Halvick, P.; Bergeat, A.; Hickson, K. M.; Wakelam, V. Review of OCS Gas-Phase Reactions in Dark Cloud Chemical Models. Mon. Not. R. Astron. Soc. 2012, 421, 1476-1484.

(41) Black, G.; Jusinski, L. E.; Slanger, T. G. Rate Coefficients for CS reactions with $\mathrm{O}_{2}, \mathrm{O}_{3}$ and $\mathrm{NO}_{2}$ at $298 \mathrm{~K}$. Chem. Phys. Lett. 1983, 102, 64.

(42) Wood, W. P.; Heicklen, J. J. Phys. Chem. 1971, 75, 854-860.

(43) Barnes, E. C.; Petersson, G. A.; Montgomery, J. A., Jr.; Frisch, M. J.; Martin, J. M. L. Unrestricted Coupled Cluster and Brueckner Doubles Variations of W1 Theory. J. Chem. Theory Comput. 2009, 5, 2687-2693.

(44) Frisch, M. J.; et al. Gaussian 09; Gaussian: Wallingford, CT, 2010.

(45) Barker, J. R.; Ortiz, N. F.; Preses, J. M.; Lohr, L. L.; Maranzana, A.; Stimac, P. J.; Nguyen, T. L.; Kumar, T. J. D. MultiWell-2012.2; University of Michigan: Ann Arbor, MI, 2012; http://aoss.engin. umich.edu/multiwell/.

(46) Yeung, L. Y.; Okumura, M.; Zhang, J.; Minton, T. K.; Paci, J. T.; Karton, A.; Martin, J. M. L.; Camden, J. P.; Schatz, G. C. O $\left({ }^{3} \mathrm{P}\right)+\mathrm{CO}_{2}$ Collisions at Hyperthermal Energies: Dynamics of Nonreactive Scattering, Oxygen Isotope Exchange, and Oxygen-Atom Abstraction. J. Phys. Chem. A 2012, 116, 64-84.

(47) Sander, S. P.; Abbatt, J.; Barker, J. R.; Burkholder, J. B.; Friedl, R. R.; Golden, D. M.; Huie, R. E.; Kolb, C. E.; Kurylo, M. J.; Moortgat, G. K.; Orkin, V. L.; Wine, P. H. Chemical Kinetics and Photochemical Data for Use in Atmospheric Studies; Evaluation No. 17, JPL Publication 10-6; Jet Propulsion Laboratory: Pasadena, CA, 2011; http://jpldataeval.jpl. nasa.gov.

(48) Montgomery, J. A., Jr.; Frisch, M. J.; Ochterski, J. W.; Petersson, G. A. A Complete Basis Set Model Chemistry. VI. Use of Density Functional Geometries and Frequencies. J. Chem. Phys. 1999, 110, 2822-2827.

(49) McKee, M. L.; Wine, P. H. Ab Initio Study of the Atmospheric Oxidation of $\mathrm{CS}_{2}$. J. Am. Chem. Soc. 2001, 123, 2344-2353.

(50) Raja, N.; Chatha, J. P. S.; Arora, P. K.; Vohra, K. G. Rate Constants for Quenching of $\mathrm{O}_{2}(\mathrm{gg})$ with Sulfur Compounds. Int. J. Chem. Kinet. 1984, 16, 205-211.

(51) Harvey, J. N. Understanding the Kinetics of Spin-Forbidden Chemical Reactions. Phys. Chem. Chem. Phys. 2007, 9, 331-343 and "MECP Program", J. N. Harvey, ver 2, 2003.

(52) Naidoo, J.; Goumri, A.; Marshall, P. A Kinetic Study of the Reaction of Atomic Oxygen with $\mathrm{SO}_{2}$. Proc. Combust. Inst. 2005, 30, $1219-1225$.

(53) Lu, C. W.; Wu, Y. J.; Lee, Y. P.; Zhu, R. S.; Lin, M. C. Experimental and Theoretical Investigations of Rate Coefficients of the Reaction $\mathrm{S}\left({ }^{3} \mathrm{P}\right)+\mathrm{O}_{2}$ in the Temperature Range $298-878 \mathrm{~K}$. J. Chem. Phys. 2004, 121, 8271-8278.

(54) Alzueta, M. U.; Bilbao, R.; Glarborg, P. Inhibition and Sensitization of Fuel Oxidation by $\mathrm{SO}_{2}$. Combust. Flame 2001, 127, 2234-2251.

(55) Dyne, P. J.; Ramsay, D. A. Some Observations on the CS Radical. J. Chem. Phys. 1952, 20, 1055-1056.

(56) Wright, F. J. Flash Photolysis of Carbon Disulfide and Its Photochemically Initiated Oxidation. J. Phys. Chem. 1960, 64, 16481652.
(57) Callear, A. B. Flash Photolysis of Carbon Disulfide. Proc. R. Soc. A: Math. Phys. Eng. Sci. 1963, 276, 401-412.

(58) Gaydon, A. G.; Kimbell, G. H.; Palmer, H. B. Shock Tube Study of Kinetics of Decomposition of Carbon Disulphide. Proc. R. Soc. A: Math. Phys. Eng. Sci. 1964, 279, 313-326.

(59) De Sorgo, M.; Yarwood, A. J.; Strausz, O. P.; Gunning, H. E. Can. J. Chem. 1965, 43, 1886-1891.

(60) Olschewski, H. A.; Troe, J.; Wagner, H. G. Unimolekularer Zerfall von $\mathrm{CS}_{2}$ in Stosswellen. Z. Phys. Chem. 1965, 45, 329-338.

(61) Arnold, S. J.; Kimbell, G. H. Reactions of Shock-Heated Carbon Disulfide-Argon Mixtures. 2. Kinetics of Dissociation of Carbon Disulfide. J. Phys. Chem. 1970, 74, 8.

(62) Olschewski, H. A.; Troe, J.; Wagner, H. G. Untersuchung Unimolekularer Reaktionen bei Hohen Drucken in Stosswellen Zerfall von $\mathrm{CS}_{2}$ und $\mathrm{CO}_{2}$. Ber. Bunsen-Ges. Phys. Chem. 1966, 70, $1060-1064$.

(63) Saito, K.; Toriyama, Y.; Yokubo, T.; Higashihara, T.; Murakami, I. A Measurement of the Thermal Decomposition of $\mathrm{CS}_{2}$ behind Reflected Shock Waves. Bull. Chem. Soc. Jpn. 1980, 53, 1437-1438.

(64) Woiki, D.; Roth, P. Shock Waves 1994, 4, 95.

(65) Woiki, D.; Roth, P. A shock tube study of the reactions of $\mathrm{H}$ atoms with COS, $\mathrm{CS}_{2}$, and $\mathrm{H}_{2} \mathrm{~S}$. Isr. J. Chem. 1996, 36, 279-283.

(66) Singleton, D. L.; Cvetanovic, R. J. Evaluated Chemical Kinetic Data for the Reactions of Atomic Oxygen $\mathrm{O}\left({ }^{3} \mathrm{P}\right)$ with Sulfur Containing Compounds. J. Phys. Chem. Ref. Data 1988, 17, 13771437.

(67) Slagle, I. R.; Gilbert, J. R.; Gutman, D. Kinetics of the Reaction between Oxygen Atoms and Carbon Disulfide. J. Chem. Phys. 1974, 61, 704-709.

(68) Graham, R. E.; Gutman, D. Temperature Dependence of Rate Constants and Branching Ratios for Reaction of Oxygen Atoms with Carbon Disulfide. J. Phys. Chem. 1977, 81, 207-209.

(69) Cooper, W. F.; Hershberger, J. F. An Infrared-Laser Study of the $\mathrm{O}(3 \mathrm{P})+\mathrm{CS}_{2}$ Reaction. J. Phys. Chem. 1992, 96, 5405-5410.

(70) Hsu, D. S. Y.; Shaub, W. M.; Burks, T. L.; Lin, M. C. Dynamics of Reactions of $\mathrm{O}\left({ }^{3} \mathrm{P}\right)$ Atoms with $\mathrm{CS}, \mathrm{CS}_{2}$ and OCS. Chem. Phys. 1979, 44, 143.

(71) Homann, K. H.; Krome, G.; Wagner, H. G. Carbon Disulfide Oxidation Rate of Elementary Reactions. 1. Ber. Bunsen-Ges. Phys. Chem. 1968, 72, 998-1004.

(72) Saheb, V. Quantum Chemical and Theoretical Kinetics Study of the $\mathrm{O}\left({ }^{3} \mathrm{P}\right)+\mathrm{CS}_{2}$ Reaction. J. Phys. Chem. A 2011, 115, 4263-4269.

(73) Froese, R. D. J.; Goddard, J. D. The $\mathrm{COS}_{2}$ Potential Energy Surface - Aspects of the Lowest Singlet and Triplet Potential-Energy Surfaces for the Reaction of Oxygen Atoms with Carbon Disulfide. J. Chem. Phys. 1993, 98, 5566-5578.

(74) Basco, N.; Pearson, A. E. Reactions of Sulphur Atoms in Presence of Carbon Disulphide Carbonyl Sulphide and Nitric Oxide. Trans. Faraday Soc. 1967, 63, 2684-2694.

(75) Woiki, D.; Roth, P. Oxidation of $\mathrm{S}$ and $\mathrm{SO}$ by $\mathrm{O}_{2}$ in HighTemperature Pyrolysis and Photolysis Reaction Systems. Int. J. Chem. Kinet. 1995, 27, 59-71.

(76) Bida, G. T.; Breckenridge, W. H.; Kolln, W. S. A kinetic study of the very fast reaction: $\mathrm{O}\left({ }^{3} \mathrm{P}\right)+\mathrm{CS} \rightarrow \mathrm{CO}+\mathrm{S}\left({ }^{3} \mathrm{P}\right)$. J. Chem. Phys. 1976, 64, 3296-3302.

(77) Lilenfeld, H. V.; Richardson, R. J. Temperature Dependence of Rate Constant for Reaction between Carbon Monosulfide and Atomic Oxygen. J. Chem. Phys. 1977, 67, 3991-3997.

(78) Rice, B. M.; Cartland, H. E.; Chabalowski, C. F. Ab Initio Potential Energy for the H+OCS Reaction. Chem. Phys. Lett. 1993, 211, 283.

(79) Adriaens, D. A.; Goumans, T. P. M.; Catlow, C. R. A.; Brown, W. A. Computational Study of Carbonyl Sulphide Formation on Model Interstellar Dust Grains. J. Phys. Chem. C 2010, 114, 18921900.

(80) Azatyan, V. V.; Novozhilov, B. V.; Posvyanskii, V. S.; Semenov, N. N. Rate and Propagation Limits of the Cool Flame Oxidation of Carbon Disulfide. Kinet. Katal. 1976, 16, 1386-1394. 
(81) Azatyan, V. V. The Role of a Reaction of Direct Substitution for a Sulfur Atom in the $\mathrm{CS}_{2}$ Molecule in the Combustion of Carbon

Disulfide with Oxygen. Kinet. Catal. 2003, 44, 459-462. 